\title{
Mucosal Vaccination against Enteric Pathogens in the Developing World
}

\author{
William Langridge ${ }^{1^{*}}$, Oludare Odumosu ${ }^{1}$, Somen Nandi ${ }^{3}$, \\ Raymond Rodriguez ${ }^{3}$, Marino DeLeon ${ }^{1}$ and Zaida Cordero-Maclntyre ${ }^{2}$ \\ ${ }^{1}$ Department of Biochemistry and Center for Health Disparities and Molecular Medicine, \\ Loma Linda School of Medicine, Loma Linda University, Loma Linda CA. 92354. \\ ${ }^{2}$ School of Public Health, Loma Linda University, Loma Linda CA, 92354. \\ ${ }^{3}$ Global HealthShare, Department of Molecular \& Cellular Biology, College of Biological \\ Sciences, University of California, Davis, Davis, CA 95616.
}

STATEMENT OF CONTRIBUTION

All co-authors have contributed to the study design, data search and analysis, and write-up of the manuscript.

Review Article

Received $22^{\text {nd }}$ September 2011

Accepted $20^{\text {th }}$ December 2011 Online Ready $25^{\text {th }}$ March 2012

\section{ABSTRACT}

Of the approximately 9 million children under the age of $5 \mathrm{yr}$ that die annually in developing nations, about 5.1 million will die from preventable infectious diseases. This disastrous human and economic loss is caused in large part by three types of acute diarrhea and attendant respiratory tract infections that are responsible for approximately 2.6 million of these deaths. Thus, enteric pathogens remain a major factor contributing to persistent poverty and poor health in developing nations. Novel mucosal vaccination strategies are emerging that can protect epithelial surfaces and therefore promise a simple, effective and safe interventional therapy to overcome the mortality generated by these debilitating infectious diseases. Before the full potential for mucosal vaccination against enteric diseases can be realized, the innate immune system must be strengthen by addressing secondary problems such as malnutrition, malabsorption and gastrointestinal tract impairment.

Here we describe the major enteric pathogens responsible for childhood morbidity and mortality in developing and resource-limited countries. We also discuss the development of mucosal vaccination strategies that when combined with modern principles of 
nutritional therapy may help improve the health and socio-economic status of developing nations.

Keywords: Poverty, malnutrition; immunostimulation; enteric disease; parasites; rotavirus mucosal vaccines; health disparities.

\section{INTRODUCTION}

For protection against the ravages of infectious microorganisms, vaccines have proven to be man's most effective therapeutic. For example, Jenner's smallpox vaccine, Salk's polio vaccine and the now ubiquitous DPT vaccine effective against infection by three lethal childhood diseases diphtheria, pertussis and tetanus. While, traditional killed or attenuated pathogen parenteral vaccines are generally effective in healthy people, they may pose a variety of problems for healthy people and especially to the immuno-compromised and those living in absolute poverty in developing nations. Problems that still plague injected vaccines include the continuous requirement for refrigeration to preserve vaccine efficacy, the need for trained personnel for vaccine delivery, the potential for infectious disease transmission among vaccines through contaminated needles, pain and inflammation due to needle stick injury and the risk of exposure to animal products required for vaccine preparation that may stimulate allergy, autoimmunity or carry mammalian diseases. Infectious microorganisms that are of greatest concerns to developing countries include those that stimulate inflammation of the digestive tract resulting in acute diarrhea. These "enteric" diseases are responsible for the loss of more than two million children annually, in developing countries. The major cause of enteric disease induced death is the rapid loss of water from the body, which leads to dehydration and a dramatically increased potential for cardiac arrest. In new borns, injected vaccines may induce long-term immunotolerance. The whole-cell pertussis vaccine (DTP) given at birth was shown to induce persistent B-cell hypo-responsiveness against pertussis antigens (Cerkinsky and Holmgren, 2009). However, the live-attenuated vaccines Bacillus Calmette-Guérin (BCG) against tuberculosis and oral polio vaccines were shown to consistently induce protective immunity following a single immunization at birth (Cerkinsky and Holmgren, 2009). In contrast to parenteral vaccines, mucosal vaccines are generally more effective for extracellular pathogens that live in the blood and lymph like Vibrio cholera and enterotoxigenic Escherichia coli(ETEC) that enter the peripheral circulation via the intestinal epithelia. Oral vaccines have been shown to be effective against intracellular viral pathogens such as rotavirus and poliovirus. Since the development of an oral vaccine for poliomyelitis (OPV) by Salk in 1952, conventional attenuated pathogen based oral vaccines have become available for treatment of several major enteric diseases and include oral rotavirus vaccines (Rotarix, Galaxo-Smith Kline, Inc.) and (RotaTeq, Merck, Inc.), vaccines for cholera (Dukoral, Crucell Inc., and Orochol (Mutachol), Berna Biotech Ltd.) and oral vaccines for Salmonella typhimurium (Vivotif Oral, Berna-Crucell Ltd.). In addition to conventional parenteral vaccines that generate $\operatorname{lgM}$ and IgG antibodies, oral vaccines have the special advantage of producing large amounts of antibodies $(\lg A)$ secreted into the intestine which permits interception of pathogens in the lumen of the intestine prior to their colonization of the intestinal mucosa. These vaccines are based largely on intact attenuated or reassorted pathogens and therefore contain many nonimmunogenic pathogenic proteins, which may be toxic or result in reactogenicity and other undesirable forms of inflammation. To circumvent these problems, a novel subunit vaccine strategy is under development which selects individual pathogen proteins that are strongly 
immunogenic and which avoids the presence of toxic pathogen proteins. However, such vaccines delivered to the patient orally often generate weak immunogenic responses and benefit greatly through co-delivery with immunostimulatory molecules (adjuvants). More recently safe, multi-component subunit vaccines genetically linked with protein adjuvants are becoming available and are effective for prevention of infectious disease from more than one enteric pathogen. While these vaccines have demonstrated efficacy in pre-clinical animal studies, their ability to protect patients has yet to be determined.

To be effective, oral-vaccines must overcome a number of problems including the acidic environment of the stomach and degradation by intestinal hydrolytic and proteolytic enzymes like trypsin and chymotrypsin. Oral vaccines also need to be efficiently transported through microfold (M) cells of the gut epithelium for uptake by antigen presenting cells (e.g., primarily dendritic cells and macrophages), of the innate immune system. A wide variety of delivery systems remain under development and include virus coat proteins, virus-like particles, liposomes, slow release antigen coatings to retard vaccine digestion, protective micro- (or nano-) particles and immuno-stimulating complexes (ISCOMS). Natural vaccine delivery systems such as edible plant tissues may provide nutrition in addition to immunotherapy. To enhance epithelial cell uptake, newer vaccine formulations include epithelial cell attachment proteins such as the cholera toxin B subunit and linkage of vaccine antigens to safe adjuvants such as CTB-rotavirus toxin fusion proteins to stimulate enhanced immunological responses (Yu and Langridge, 2001). These mucosal adjuvants may safely direct and activate innate dendritic cell (DC) co-stimulatory and pro-inflammatory cytokine responses that if required, may be further modulated by dendritic cell directed adaptive $T$ cell immune responses. Ligands for toll-like receptors (TLR) such as the cholera toxin B subunit and the heat sensitive enterotoxin B subunit from enterotoxigenic E. coli (LTB), and endogenous human immunomodulators (e.g., IL-1) can stimulate DC activation to strengthen innate and adaptive immune responses. Further, mucosal adjuvants have been shown to be more effective when linked with antigens and thus are taken up and processed by the same antigen presenting cells, most frequently DCs (Yu and Langridge, 2001).

An example of a genetic engineered multi-component vaccine that has been shown to be effective in animal models of infectious diarrheal diseases is presented in Figure 1 (Yu and Langridge, 2001). Such multi-component vaccines could provide treatment of three major diarrheal causing diseases. This vaccine contains genes encoding the enterotoxin B subunit from Vibrio cholera, the enterotoxin from rotavirus and the fimbrial attachment antigen from enterotoxigenic $E$. coli and is capable of protecting mammals against infectious disease spread by these three enteric pathogens.To date, orally delivered subunit vaccines frequently generate relatively low titers in human subjects and may be more effective in disease prevention rather than treatment. To increase the levels of immunity, the strategy of linking pathogen antigens to available protein adjuvants is becoming more accepted as a safe way to improve subunit vaccine immunity. However, before optimum levels of immune protection can be expected through dissemination of subunit vaccines in low-income and developing countries, a variety of additional factors related to the pathogen and parasite load as well as the nutritional and immunological status of the population to be immunized, must be thoroughly considered. Clearly, nutritional rehabilitation and the removal of parasites prior to vaccination against bacterial and viral enteric pathogens may prove to be essential to improve vaccine protection against enteric pathogens. 


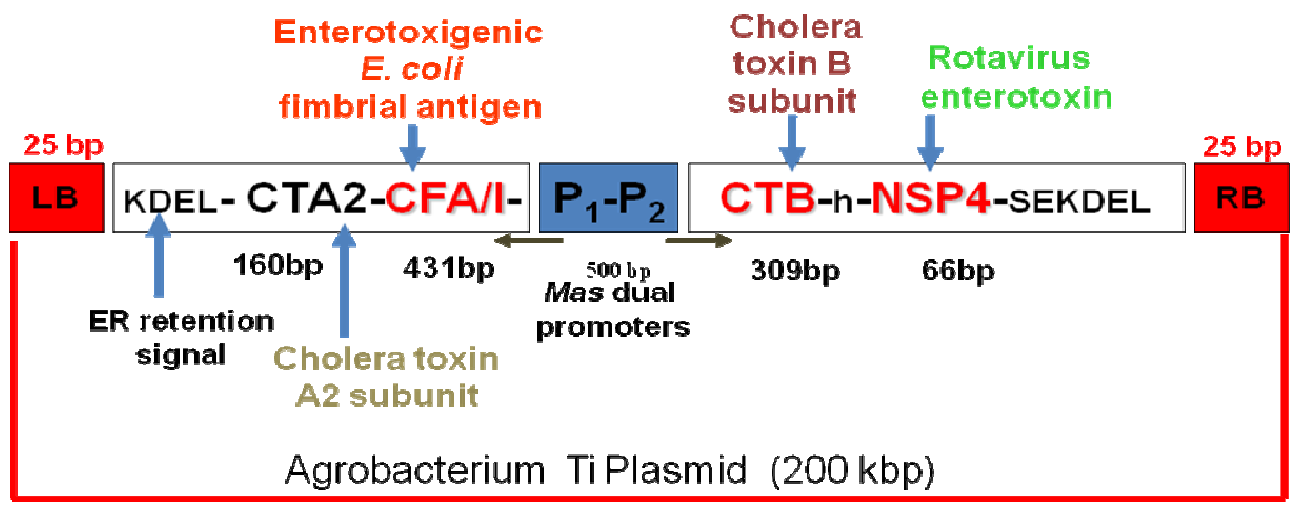

Figure 1. Multi-component Vaccine plant expression vector pPCV701CFA/I-CTB-NSP4 contains four genes located within the Agrobacterium tumefaciens transferred (T-DNA) sequence flanked by the right and left T-DNA border 25bp direct repeats (RB and LB), required for integration of the Agrobacterium T-DNA sequence into plant genome. The CTB:NSP4:SEKDEL fusion gene encodes the cholera toxin B subunit carrier gene fused to a DNA fragment encoding the invariant rotavirus enterotoxin non structural protein (NSP4) gene sequence. The fusion gene is driven by the Agrobacterium mannopine synthase (mas) dual promoter region (P2) capable of driving expression of the fusion gene in the plant. The CFA/I:CTA2 enterotoxin $E$. coli fimbrial antigen gene (CFA/1) is linked to a DNA sequence encoding the cholera toxin subunit linking A2 helical peptide (CTA2). Transcription of this gene fusion is initiated through the mas P1 promoter. The KDEL amino acid sequences linked to the 3' C-terminus of each fusion gene were attached to increase the level of fusion protein accumulation in the cell through retrograde transfer of the fusion proteins from the Golgi apparatus back to the endoplasmic reticulum.

\section{THE CO-DOMINANT PROBLEMS OF INFECTIOUS DISEASE AND MALNUTRITION}

Approximately 9.0-10.6 million deaths occur annually in children under five years of age in developing countries. Of these deaths, malnutrition is directly or indirectly responsible for $53 \%$ (5.6 million). Further, malnutrition contributes substantially to about half of the deaths due to respiratory diseases (predominantly pneumonia), associated with infectious diseases among children (WHO, 2005; Guerrant et al., 2008). In addition, both external and internal parasites play an important role in draining the host's energy resources, by depleting productivity and contributing to the continuous downward trend of malnutrition, malabsorption, Gastro-intestinal (GI) impairment followed by secondary infections, wasting, stunting, cognitive impairment and chronic disease (Dewey 2011, Rodriguez 2011). Taken together, these conditions lead ultimately to absolute poverty and early death. The results of a meta analysis of a ten cohort study showed that of the deaths in young children attributable to the condition of undernutrition, approximately $44 \%$ were due to measles, and $60.7 \%$ due to diarrhea (Caufield, 2004). Further, Gates recently showed that of the 8.8 million childhood deaths that occurred in developing countries in 2010, approximately $28 \%$ resulted from diarrhea infections and pneumonia that occurred largely as a result of lowered immune system resistance due to diarrheal illness (Figure 2). 


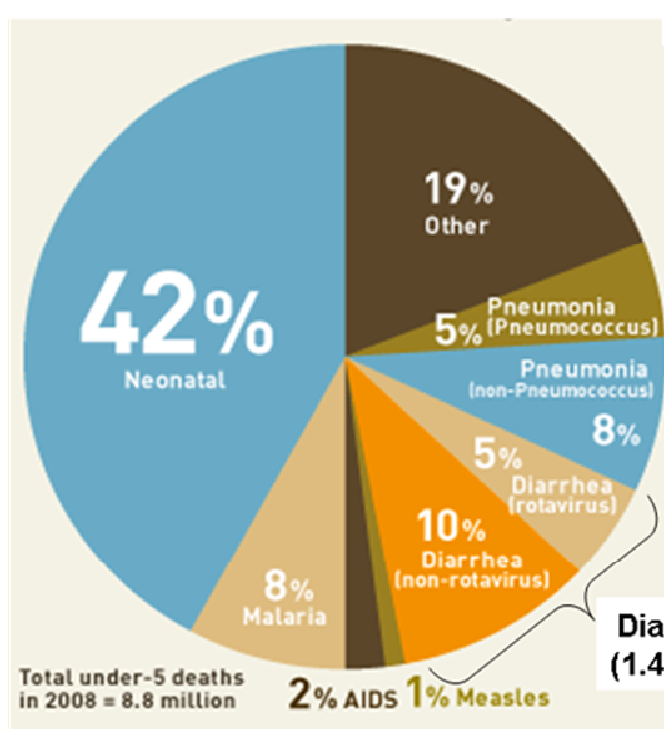

Preliminary estimates by the child Health Epidemiology Reference Group of WHO andUNICEF
Figure 2. Distribution of major infectious diseases in children under $5 \mathrm{yr}$ of age in the developing world. About $42 \%$ of new borns die before 30 days due to birth asphyxia, pre-term births, or neonatal infection (3.8 million). Problems with no present cures. Pneumonia (often sequellae to diarrhea), contributes another $13 \%$ or about 1.2 million deaths for a total of 2.6 million annual deaths due to or resulting from three major enteric infections.

\section{Diarrhea (15\%) \\ (1.4 million / yr) $\{2$ 2. Cholera \\ 3. Rotavirus}

- B. Gates, 2010 Annual Letter

Earlier studies found a strong association between initial nutritional status and duration or severity of an infectious disease episode (Guerrant, 1992). Because of the vicious cycle of undernutrition, immunosuppression and infection, more than 1 billion people or $15 \%$ of the world's population go to bed sick and hungry. This situation impedes social and economic development as well as threatens global peace and security.

There is a synergistic effect between malnutrition and infection (Scrimshaw, Interactions of Nutrition and Infection. Geneva: WHO, 1968). The World Food Summit on Food Security CFS of the Food and Agricultural Organization FAO in Rome in November 2009 called for: "Regular inclusion of structured food security and nutrition-related expertise to help create synergies between world class ACADEMIC/ SCIENTIFIC knowledge, field experience, knowledge from social factors and practical application in various settings." (World Summit on Food Security Nov, 2009).

\section{COMPONENTS OF MALNUTRITION}

Infants in developing countries are especially vulnerable to infection as their digestive tracts are free from commensal bacteria that aid digestion and compete for nutrients with invading pathogens. The lack of breast-feeding neonates in developing countries may deprive the infant of protective chemokines and cytokines and additional immune factors delivered by the mother to infants through her breast milk. One positive aspect for vaccination may be that the mother may likely have developed protective antibodies to enteric pathogens that could through her breast milk, interfere with the ability of vaccines to provide a protective immune response. 
Malnutrition in developing countries has two major components, (1) Macronutrient deficits, especially protein deficiency (kwashiorkor), which is manifested by bipedal edema and 2)
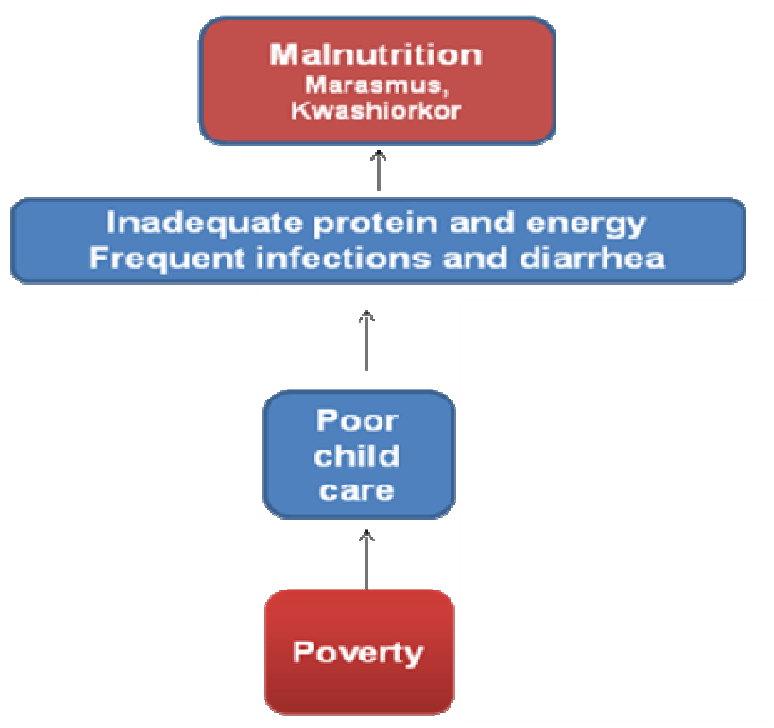

Figure 3. Socio-economic Links to Poverty and Malnutrit In Developing Countries

general starvation.

Marasmus, which is manifested by both energy and protein deficiencies, which leads to a decrease in muscle mass (e.g., wasting). Finally there is a combination of the two (marasmickwashiorkor), typified by both wasting and edema. (2) Other forms of undernutrition include micronutrient deficiencies such as iron, iodine, vitamin A and zinc deficiencies. Although poverty is the underlying cause of malnutrition in the developing world, there are additional political and socioeconomic factors that can determine the overall health of a community. These factors include education, sanitation, food production, food preparation, cultural practices, religious beliefs and access to health services. It is the interaction and interconnectedness of all these factors that ultimately determines the nutritional status of populations and the development and persistence of infection as described in Figure 3. Thus, co-administration of vaccines with agents that increase the physiological status of the intestine, such as zinc or vitamin A, may increase vaccine immunogenicity. Indeed, a recent study involving Bangladeshi men with low vitamin A stores showed that increasing vitamin A above the level required for normal vision enhances some measures of T-cell-mediated immunity (Ahmad et al., 2009; Duriancik et al., 2010; Strober, 2008; Ahmad et al., 2009).

\section{EPIDEMIOLOGY}

Statistics show that about 852 million people in the world were undernourished in 20002002, the largest population being about 815 million people living in developing countries. In children, protein-energy malnutrition is diagnosed using anthropometric measurements such as weight for age (underweight), height for age (stunting) and weight for height (wasting). Children that fall below 3 standard deviations $(<3$ SD) are diagnosed as having severe acute malnutrition. Recent weight loss is indicative of wasting, whereas chronic weight loss indicates stunting. 
Table 1. Factors that contribute to the prevalence of enteric diseases include poor

\section{Table 1. Severe Malnutrition}

\section{Blood Measurements}

- Hemoglobin. hematocrit. erythrocyte count, mean corpuscular volume.

- Glucose

- Electrolytes and alkalinity ( $\mathrm{Na}, \mathrm{K}, \mathrm{HCO} 3 . \mathrm{pH})$

-Total protein, transferrin, pre-albumin

- Creatinine

- Lymphocyte count, c-reactive protein

- Serology. thick and thin blood films

sanitation, pathogen competition for intestinal flora dominance leading to morphological changes in intestinal cells characterized by increased levels of inflammation and reduction or loss of intestinal epidermal cell microvilli all leading to increased levels of nutrient malabsorption exacerbated by conditions of deep poverty. Collectively, these conditions are being referred to as environmental enteropathy ( $T$. Ahmed, per. comm.) Thus, children living under these socio-economic conditions with an inexperienced immune system are especially prone to long-term negative health outcomes.

\section{CLINICAL INDICATORS}

Infection complicates the problem of protein-energy malnutrition, especially if diarrhea and

Table 2.

Factors in the

Management of Protein and Energy Malnutrition

- Hyperthermia

- Hypoglycemia

- Dehydration

- Micronutrients

- Infection

- Parasites

- Electrolytes

- Starter nutrition

- Tissue building

- Stimulation

- Prevention of relapse intestinal parasites are present. Clinical changes observed are immunological deficiencies in the humoral and cellular systems, and a decrease in humoral mediators such as tumor necrosis factor. Changes in the immune system and especially in the thymus are related to the impaired peripheral immune response seen in malnourished and infected individuals. Thus, strategies inducing thymus replenishment should be considered as adjuvant therapeutics to improve immunity in malnutrition and/or acute infectious diseases (Savino and Dardenne, 2010). Clinical indicators of marasmus are loss of subcutaneous fat and muscle, triangular face, amenorrhea, extended abdomen due to muscular hypotonia) due to loss of perianal fat. Kwashiorkor's clinical signs include edema, changes to hair and skin color, anemia, hepatomegaly, lethargy, immune deficiency and early death. In marasmic-kwashiorkor, there are changes in hair and skin pigment due to lack of substrate (tyrosine). In severe protein-energy malnutrition a variety of metabolic changes occur, Table 2. Degeneration of visceral organs compounds the problem; fatty degeneration of heart and liver compromise their function. Cardiac insufficiency may result in fluid and sodium overload, which can lead to cardiac failure. The loss of subcutaneous fat results in impaired body temperature control. Atrophy of the intestinal mucosa leads to decrease absorption and digestion. In the field, malnutrition may be diagnosed by anthropometric measurements, and when possible laboratory analysis used (Ashworth et al., 2004). Molecular biomarkers predictive of protein-energy malnutrition, particularly stable metabolite from non-invasive fluids, could aid in the early diagnosis of wasting and stunting before irreversible damage to the Gl tract and brain have occurred. 


\section{MALNUTRITION AND ENTERIC INFECTIONS}

Enteric infections can impair the absorption of nutrients. If the infection is exacerbated by malnutrition, the results will be devastating in terms of damage to critical systems of the body. Malnutrition and Infection comprise a vicious cycle in which malnutrition encourages infection and infection, through destruction of the villus architecture, worsens malnutrition. Diarrhea alone significantly impairs children's weight and height resulting in stunting of growth (Guerrant et al., 2008; Muller and Krawinkel, 2005).

\section{MALNUTRITION MANAGEMENT}

To provide adequate nutritional therapy a number of nutritional elements must be carefully assessed (Table 2). Nutritional assessment is necessary to avoid the possibility of Refeeding Syndrome, a condition caused by rapid re-feeding after a person who has undergone a period of severe malnutrition. Refeeding Syndrome can be fatal but completely preventable with proper management of nutrition rehabilitation. Those at highest risk are persons with little or no intake for a period of 10 days or more. Metabolic and hormonal abnormalities can occur that include hypophosphatemia, hypokalemia, hypomagnesemia, hyperglycemia with osmotic diuresis, vitamin deficiency (e.g., thiamine). Because intake of carbohydrate may decrease renal excretion of sodium and water the administration of fluids to patients may cause fluid retention and contribute to cardiac failure (Hisham et al., 2009; Mehler et al., 2010).

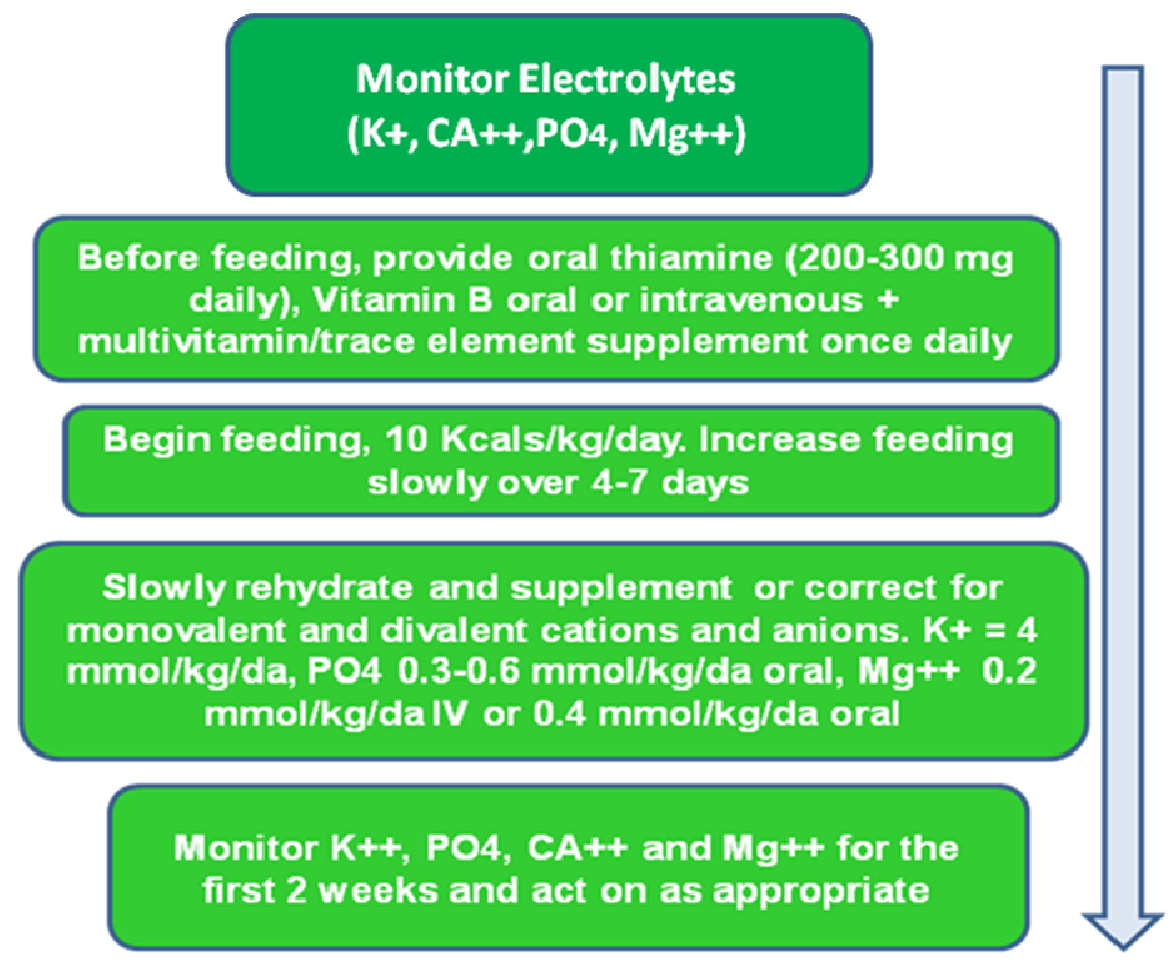

Figure 4. Regime for initiation of restorative therapy 
Thus, a several physiological parameters must be assessed prior to initiating restorative therapy, Figure 4 (adapted from Hisham Mehanna, Paul C Nankivell, Jamil Moledina, and Jane Travis. 2009 in Head Neck Oncol.; 1: 4. An excess of 1 $\mathrm{g} / \mathrm{kg} / \mathrm{bw}$ of protein combined with impaired liver function and decreased urine output, exceeds the capacity of a malnourished child to metabolize normal ammonia loads (Hisham et al., 2009).

\section{STEPS IN REHABILITATION}

The continuous stimulation of antigen presenting cells of the innate immune system by bacterial pathogens and parasites (helminths) in the intestinal mucosa can result in overstimulation of the innate immune system leading to a chronic inflammatory state. Nutrient deficiencies especially vitamin A (retinoic acid) can retard the maturation and expansion of cells of the innate and ultimately the adaptive arms of the immune system e.g., dendritic cells, $T$ helper cells and cytotoxic $T$ cells, leading to exacerbation of chronic inflammation. The process of nutritional rehabilitation requires passive steps such as: a.) the screening of participants, b.) education on nutrition, c.) education concerning sanitation, as well as active steps including d.) treatment for parasitosis: helminthes, e.) Initiation of nutrition rehabilitation, f.) Immunization using transgenic vaccines, and g.) follow up analyses to assess patient progress. In response to infection, the human immune system initially activates innate dendritic cell and macrophage immune responses and if found to be ineffective, subsequently activates adaptive lymphocyte mediated and B cell host defense responses. Both innate and adaptive immune responses involve activation and propagation of immune cells (macrophages, B cells, natural killer cells and CD4+ and CD8+T lymphocytes), as well as a variety of molecules (e.g., cytokines) and transcription factors requiring gene expression and protein synthesis that consume additional host reservoirs of energy. The generation of inflammatory responses further increases the energy drain. Thus, the nutritional status of the host plays a major role in the outcome of infection. Further, deficiencies in individual nutrients, such as vitamins $A$ and $D$, fatty acids, amino acids, zn, iron, and trace elements, contribute to a lack of nourishment in addition to deficiencies in protein energy metabolism (PEM). This greatly increases human susceptibility to major infectious diseases that cause diarrhea and that can be readily observed in children living in resource-limited countries such as sub-Saharan Africa, Central and South America South Asia and Southeast Asia (Scrimshaw, 1997; Ambrus, 2004; Woodward, 1998).

\section{MALNUTRITION INCREASES THE RISK OF INFECTION}

The presence of protein and energy starvation (PEM) in children clinically defined as less than $70 \%$ weight-for-height ratio is described as marasmus, and leads to a chronic wasting condition. Alternatively, sufficient carbohydrate intake with a deficiency in protein characterized by edema and anemia (kwashiorkor) is found in sub-Saharan Africa. Malnutrition during childhood often affects thymic development, which compromises immunity in children by long-term reduction in the number of peripheral lymphocytes (Savino, 2002). This deficiency in immunity represents a key factor in susceptibility to infections (Beisel, 1996). In severely malnourished patients, both lymphocyte functions as well as innate host defense mechanisms including macrophage and granulocyte proliferation and maturation are inhibited. Decreased immune functions render undernourished patients more susceptible to infections by opportunistic pathogens commonly found in patients with HIV (Scrimshaw, 1997; Ambrus, 2004; Woodward, 1998; Field, 2002; Cegielski, 2004). An opportunistic infection in children between one and four years occurring with PEM, known as Noma, occurs worldwide, but most commonly in sub-Saharan Africa and evolves from 
gingival inflammation to orofacial gangrene and is commonly preceded by other infections such as measles, malaria, severe diarrhea, and necrotizing ulcerative gingivitis. Noma often coincides with the period of linear growth retardation in malnourished children (Enwonwu, 2006). In addition to promoting acute and chronic infections, PEM impairs the linear growth of children, leading to a further reduction in food intake, nutrient absorption, direct or catabolic nutrient losses, and increased metabolic requirements (Stephensen, 1999). The correlation between malnutrition and growth retardation allows assessment of the individual nutritional state, which is usually measured as mid-upper arm circumference or body mass index (BMI). BMls are given either as weight-for-height to indicate acute PEM (wasting), or as weight for-age (underweight) or height for-age (stunting), correlations for chronic PEM.

\section{INFECTION ALSO CONTRIBUTES TO MALNUTRITION}

Gastrointestinal infection with enteric pathogens can lead to chronic diarrhea and failure to thrive. Tuberculosis, HIV infection, and other chronic infections may cause cachexia (wasting disease - loss of appetite) and anemia. Further, intestinal parasites can cause anemia and nutrient deprivation (Scrimshaw, 1968). Stimulation of an immune response by infection increases the demand for metabolic energy leading to progressively worse cycles of adverse nutritional status and increased susceptibility to infection. A study in Nigeria found that metabolic demands made during acute measles infection further deteriorated the condition of malnourished children, leading to further weight loss, wasting, and reduced serum levels of essential amino acids (Phillips, 2004). Increased energy consumption due to immune responses may also affect the efficacy of live attenuated vaccines in populations with PEM. Arginine treatment was shown to improve nitrogen balance and lymphocyte function. These benefits have made arginine an essential constituent of immunonutritive formulas currently in use for critically ill patients. Therefore, nutritive management nutritional quality and composition are critical for anti-infectious immunity.

\section{HOW MALNUTRITION AFFECTS IMMUNITY}

Severe protein malnutrition in newborns and small children causes atrophy of the thymus with reduced cell numbers and subsequently ill developed peripheral lymphoid organs, (i.e., lymph nodes and spleen) (Savino, 2002). This causal chain leads to long lasting immune defects characterized by leucopenia, decreased CD4 to CD8 ratio and increased numbers of CD4/CD8 double-negative $T$ cells and therefore, the appearance of immature $T$ cells in the periphery. Malnourished children suffer in greater proportion from respiratory infections, infectious diarrhea, measles, and malaria, characterized by a protracted course and intensified infection. The epithelial barrier of the undernourished host is compromised due to altered architecture of the gut mucosa, such as flattened hypotrophic microvilli, reduced lymphocyte counts in Peyer's patches, and reduced immunoglobulin A (IgA) secretion (Beisel, 1996). The availability of complement is restricted by malnutrition, thereby affecting the capacity of phagocytes to engulf and eliminate pathogens. In mice with experimental PEM, phagocytosis and production of reactive oxygen intermediates (ROIs) and reactive nitrogen intermediates (RNIs) by macrophages is diminished, as is antigen presentation to T cells by dendritic cells (Abe, 2003). Peripheral T lymphocytes from infected children with PEM had lower expression of the activation marker CD69, and predominantly showed an intermediate (CD45RAlow/CD45ROlow) rather than a memory phenotype (CD45ROhigh) when compared to healthy donors (Najera, 2001; Najera, 2004). These T cells were biased towards type $2 \mathrm{~T}$ helper cell (Th2) responses, represented by decreased IFN- $\mathrm{\gamma} / \mathrm{LL}-2$ (type $1 \mathrm{~T}$ helper cell (Th1)) and increased IL-4/IL-10 (Th2) production (Rodriguez, 2005). 
Experimentally undernourished weanling mice had predominantly $T$ cells of the naïve quiescent phenotype (CD45RA+/ CD62L+) (Woodward, 1999; ten Bruggencate, 2001). In these mice, IFN- $\gamma$ responses were depressed and IL-10 and the Th2-associated antibody, IgE, were increased, while IL-4 production remained normal (Neyestani, 2005). PEM appears to alter immune responses, thus hampering protective immunity of any type. Protective $T$ cell responses against helminth infections are predominantly of the Th2 type comprising IL-4 production, expansion of eosinophils, and $\mathrm{IgE}$ secretion. However, malnourished children are deficient for protective $\operatorname{lgE}$ antibodies against Ascaris lumbricoides (Hagel, 1995; Hagel, 2003). By suppressing such responses in mice, PEM increases susceptibility to infection with the intestinal parasite, Heligmosomoides polygyrus (Ing, 2000). Malnourished children suffering from helminth infections have high concentrations of total lgE. Yet these antibodies are neither worm-specific nor protective, and their memory T cells do not recognize helminth antigens (Hagel, 2003; Ing, 2000). Malnutrition can be considered an important risk factor for morbidity and mortality worldwide due to infections with bacterial, viral, and protozoa (Scrimshaw, 1997; Field. 2002; Cegielski, 2004; United States Department of Health and Human Services, 1988).

Malnutrition is a common problem among children in countries of sub-Saharan Africa, Central and South America and South and Southeast Asia including India and Bangladesh. These children will benefit most from improved nutrition and an increased ability to resist childhood diseases, acute diarrheal diseases, and ultimately the big three infectious diseases, malaria, tuberculosis and HIV infection indigenous to these geographical areas. Current WHO values for malnutrition in sub-Saharan African countries, Central and South American countries and South Asia and Southeast Asian countries will provide data validating our perception of the problems of malnutrition and death by various childhood and adult borne infectious diseases. Vaccination of children in these areas against diarrheal diseases eventually including malaria, tuberculosis and HIV will protect the great majority of the children and adults. However, before vaccination can become truly effective, it will be necessary to examine and improve nutritional status so the person's immune system will be able to translate vaccination against infectious diseases into a protective immune response (e.g. mature $T$ cells into $T$ helper lymphocytes and cytotoxic $T$ cells), to adequately fight against diseases.

\section{IMMUNE-ENHANCING NUTRITIONAL SUPPLEMENTATION}

Immune-enhancing nutrients are a group of chemically heterogeneous substances. Only a small number of clinical trials evaluate the efficacy of a single agent while most studies examine various combinations of these nutrients. We have included studies that compared enteral nutrition containing at least 2 or more of the 4 most frequently used immuneenhancing nutrients (arginine, glutamine, omega-3 fatty acids, or nucleotides) by standard enteral nutrition only. One study assessed nutritional supplementation on recovery of 50 critically ill children given an immune-enhancing formula (I) or conventional early enteral nutrition (C). Recovery was compared based on improvements in nitrogen balance (NB), nutritional indices, and antioxidant catalysts (Briassoulis, 2005). Caloric intake was aimed at meeting patient's predicted basal metabolic rate by day 2 and predicted energy expenditure by day 4, irrespective of group assignment. Outcome endpoints and complications were recorded; NB, transthyretin, retinol-binding protein, transferrin, zinc, copper, and metabolic indices were measured on days 1 and 5 and compared with clinical and nutritional characteristics within and between groups. Both diets achieved their initial targets of covering predicted basal metabolic rate by day 2 and predicted energy expenditure by day 4 . Twenty four-hour NB became positive in $40 \%$ of patients in group C and occurred in $64 \%$ of 
patients in group I by day 5 . Only in group I did the mean NB become positive by day 5 ( 0.07 $\pm 0.07 \mathrm{~g} / \mathrm{kg}$ versus $-0.24 \pm 0.03 \mathrm{~g} / \mathrm{kg}$ on day $1, P<0.001)$ compared with group $C$ in which the mean NB remained negative $(-0.06 \pm 0.04 \mathrm{~g} / \mathrm{kg}$ versus $-0.25 \pm 0.06 \mathrm{~g} / \mathrm{kg}$ on day $1, P<$ $0.001)$. By day 5 , nutritional indices and antioxidant catalysts showed a higher increasing trend in group I compared with group $C$ and higher osmolality $(P<0.02)$, sodium $(P<0.03)$, and urea $(P<0.04)$. Diarrhea for group I $(P<0.02)$ and gastric distention for group $\mathrm{C}(P<0.04)$ were the most frequently recorded complications. Mortality or length of stay did not differ between groups, but there was a trend for less gastric gram plus isolates $(P<0.05)$ or for Candida species $(P<0.04)$ and nosocomial infections in group I compared with group $\mathrm{C}$. Although less well tolerated, immuno-nutrition is a feasible method of early enteral nutrition in pediatric intensive care. It has a favorable effect on nutritional indices and antioxidant catalysts. Although it poses a higher metabolic burden to the patient, it shows a trend to improve colonization and reduce infection rates. Appropriate modifications for specific age populations might improve its tolerability and benefits among critically ill children.

Twenty-two randomized trials with a total of 2419 patients compared the use of immunonutrition with standard enteral nutrition in surgical and critically ill patients (Daren, 2001). With respect to mortality, the authors found that studies using commercial formulas with high arginine content were associated with a significant reduction in infectious complications and a trend toward a lower mortality rate in comparison with other immune-enhancing diets. In studies of critically ill patients, studies with a high-quality score were associated with increased mortality and a significant reduction in infectious complication rates compared with studies with a low-quality score. Thus, immuno-nutrition may decrease infectious complication rates but may not be associated with an overall mortality advantage. However, treatment effects vary depending on the intervention, the patient population, and the methodological quality of the study.

Delivery of enteral nutrition in preference to parenteral nutrition is suggested for meeting the nutritional needs of critically ill patients with functional alimentary tracts (Heyland, 1998). Several specific nutrients including arginine, glutamine, nucleotides, and omega-3 fatty acids, either alone or in combination, were shown to influence nutritional, immunological, and inflammatory parameters (Evoy, 1998; Wilmore, 1998; Hall, 1996; Leleiko, 1995; Alexander, 1998; Wu, 1998). An important observation is that many children suffering from chronic malnutrition have a very poorly functioning digestive tract, in which the intestinal epithelial cells have reduced numbers or are devoid of microvilli. Thus, nutrient absorption is drastically reduced resulting in nutrient mal-absorption following introduction of a nutrient rich diet and a resultant increase in diarrhea frequency and intensity. To circumvent this problem, an increasing number of commercially produced nutritional supplementation formulations are now available in the market place. Two of the most frequently studied formulas (Immun-Aid, McGaw, Irvine, Calif; Impact, Novartis Nutrition, Minneapolis, Minn), are similar in arginine content. It is possible however, that there could be an adverse effect caused by immunonutrition in critically ill patients with ongoing infection and sepsis due to increased production of nitric oxide as a consequence of arginine supplementation (Lorente, 1993).

\section{THE PROBLEM OF PARASITISM}

In Sub-Saharan Africa South Asia and Southeast Asia, elimination of parasite infestations will be an important factor for establishment of effective immunotherapy. Protein/energy malnutrition (PEM) and/or deficiencies of nutrients important for nucleic acid metabolism lead to widespread loss of lymphoid tissues and dysfunctions of cell-mediated immunity, especially in children. Due to the presence of parasites, the thymus, spleen, tonsils, and 
lymph nodes become atrophied (Keusch, 1993). Histological evidence of atrophy is greatest in T-lymphocyte generating tissues. Lymphocytes and eosinophils show lowered blood cell counts. Natural killer cells loose the ability to recognize and destroy foreign tissues (Chandra, 1991; Salimonu, 1993). In contrast however, B-lymphocyte numbers and functions appear to be relatively unaffected (Salimonu, 1993). Blood lymphocytes become unreactive to mitogens. Production of thymic hormones is reduced, as is the patient's ability to fend off and recover from infectious illnesses. The immune system, malnutrition, and infectious diseases become intertwined in a complex network of interactions and responses to extracellular input. Trace element deficiencies and malnutrition frequently lead to a variety of immune system dysfunctions, ineffective immunity, impaired body defense mechanisms that allow infectious diseases to flourish. These closely linked events initiate a "downward spiral" of recurrent infection that leads eventually to death (Beisel, 1995). New primary antibody responses to T-cell-dependent antigens and antibody affinity are also impaired (Chandra, 1991). New primary responses to T-cell dependent antigens are generally subnormal in magnitude and quality. Infants and small children are at great risk because they possess only immature, inexperienced immune systems and very small protein reserves. Malnourished children become anergic, with a decrease or reversal in the ratio of T-helper to suppressor cells. Broad-based efforts to improve health care access and treatment have stabilized HIV infection levels in many parts of the world and led to longer survival for people living with HIV infection. However, confounding clinical and social issues, including medication interactions, co-morbidities, wasting, lipodystrophy, food insecurity, aging, and other related conditions further complicate disease management especially in developing nations. Thus, management of chronic HIV infection continues to become more complex and demanding (J Am Diet Assoc. (2010); 110: 1105-1119.).

For optimal vaccination against infectious diseases in developing nations the problems of mosquito, sand fly and assassin bug vectors of parasitic eukaryotes leading to continuous disease and malnutrition must be resolved. Among the most important parasites in the developing world are those that invade the wall of the intestinal tract (Loukopoulos et al., 2007). Economically important intestinal parasites include two major classes, the unicellular protozoans and the multicellular parasitic worms (helminths). Of the infectious protozoans, Entamoeba, Cryptosporidium, Giardia intestinalis, Cyclospora cayetanensis, Isospora belli and microsporidia are among the most important protozoan parasites identified in humans and in other species of vertebrates (Leońska-Duniec and Adamska, 2010). They are the most frequently identified protozoans causing gastrointestinal disease worldwide in humans and especially in immunocompromised patients, children, pregnant women and the elderly. Protozoan pathogens have both anthroponotic and zoonotic transmission routes. Each parasite is able to infect the digestive tract, and spread to other organs of the body. Furthermore, two or more parasites often infect the same host. All protozoan parasite groups can be found in uncooked or unwashed food, contaminated water, or can infect their host by skin contact with larva, infested plants or soil. After ingestion, the parasites travel into the intestine, where they reproduce and cause symptoms of malaise, diarrhea, intestinal pain and irritability. Almost $60 \%$ of the approximately 1,400 recognized species of pathogens infectious to humans are zoonotic (have an alternate animal host and are transmissible between humans and animals). At least $65 \%$ of recent recorded major disease outbreaks are of zoonotic origin (National Academies' report "Sustaining Global Surveillance and Response to Emerging Zoonotic Diseases", 2009). These emerging and reemerging diseases respect no, temporal, geographic, or political boundaries. They epitomize what can be regarded as a truly global health problem (Higgs et al., 2010). 
The above indicated protozoan parasite genera, in addition to the enteric dwelling protozoan parasite genus Entamoeba, account for the majority of protozoan infections throughout both the industrially developed and economically developing nations throughout the world (Mortimer and Chadee, 2010). The following parasite and pathogen species play a major role in suppression of the patient's immune system. Improved neutralization of these pathogens will strengthen innate and adaptive immune responses to enteric diseases allowing the effects of improved nutrition and immunization to significantly decrease the patient's time for physical recovery and a reduction in social/economic burden as expressed as disability-adjusted life years (DALY).

\subsection{Entamoeba histolytica}

This pathogen is an anaerobic parasitic protozoan in the genus Entamoeba (Ryan, 2004). E. histolytica predominantly infects humans and other primates and is responsible for amoebic dysentery, colitis and amoebic liver abscesses. Annually throughout the world, there are approximately 100 million cases of amebiasis, amebic dysentery, colitis and liver abscesses resulting in about 100,000 deaths annually (Mortimer and Chadee, 2010). Amebiasis is the third leading cause of death due to parasitic disease and is a major health problem in developing countries, surpassed only by malaria and schistosomiasis for death caused by parasitic infection (WHO, 1997). E. histolytica is acquired when infective cysts are ingested through contaminated food or water. The cysts release trophozoites into the terminal ileum and from there the parasite migrates to the colon where it colonizes the mucus layer via binding to host mucin oligosaccharides with the ameba surface adhesin, Gal-lectin; (Chadee et al., 1987). With the exception of Entamoeba gingivalis, that lives in the mouth, all Entamoeba species are found in the intestines (Mortimer and Chadee, 2010). While $E$. histolytica lives primarily in the colon as a harmless commensal, it may quickly become pathogenic. What triggers the pathogenic phenotype and the onset of disease is presently an unknown part of the complex host-parasite interaction. During chronic amebiasis, the host immune response is incapable of eliminating the parasites due to parasite-mediated immunosuppression of the host (Mortimer and Chadee, 2010). Infections outside of the intestine are common, but how the parasite escapes into the circulatory system is not clearly known. In the liver, amebic infection results in the formation of multiple granulomas that expand and coalesce to form large singular abscesses (Chadee and Meerovitch, 1984). For therapy, nitromidazoles are often effective (Haque et al., 2003). E. histolytica is protected by a network of immune cells and humoral factors. In addition to degrading $\lg A$, the trophozoite can also inactivate circulating IgG (Tran et al., 1998).

\subsection{Cryptosporidia}

Cryptospridiosis is one of the most common waterborne diseases worldwide. The parasite is transmitted to mammals by oocysts causes an acute short-term infection of the intestinal epithelium after ingestion (CDC, 2009). Cryptosporidium infections are acquired through direct contact with infected persons or animals (zoonotic transmission) and by ingestion of contaminated food or water (Xiao, 2010). Transmission of C. parvum a Cryptosporidium known to infect humans is mostly anthroponotic in developing countries, and with the added opportunity of zoonotic infections also plays an important role in developed countries (Xiao, 2010). Presently, small subunit rRNA-based tools are being generally used for genotyping Cryptosporidium in humans, animals and in water samples. Five Cryptosporidium species/genotypes including Giardia intestinalis are responsible for most of the human cases of cryptosporidiosis and include C. hominis, C. parvum, C. 
meleagridis, C. felis, and C. canis (Xiao and Feng, 2008). However, zoonotic infections in humans in industrialized nations are usually of bovine origin (Xiao, 2010). The main symptom of Cryptosporidium infection is acute, watery, non-bloody diarrhea in people with intact immune systems but in immunocompromised patients these symptoms are often fatal. Symptoms of $C$. parvum infection are of particular concern in immunocompromised patients, where diarrhea can reach 10-15L per day. Additional symptoms may include anorexia, nausea, vomiting and abdominal pain (Center for Disease Control, 2007). Paromomycin and Nitazoxanide may also be used in addition to IV fluid rehydration to alleviate diarrheal symptoms but are contraindicated in immunosuppressed patients (Cabada and White, 2010). Anti-retroviral drug therapy to boost the immune system has also been used to control infection. Children and immunosuppressed individuals, especially those infected with HIV/AIDS, are more strongly affected. The numerous surface glycoproteins on $C$. parvum have been implicated in pathogenesis. Competitive inhibition using native surface sporozoite protein GP900 or purified GP900 fragments can reduce cell invasion (Barnes et al., 1998). Lectins directed against GP900 carbohydrate moieties such as alpha- $\mathrm{N}$-galactosamine were shown to block adhesion and prevent $C$. parvum invasion (Cevallos et al., 2000).

\subsection{Microsporidia}

Microsporidia are spore-forming eukaryotic unicellular fungal parasites that comprise more than 1200 species. They infect invertebrates, fish, and mammals as well as human and nonhuman primates. Since the first case of microsporidiosis diagnosed in humans in 1959 (Monaghan et al., 2009), 14 species have been reported to infect humans resulting in more severe symptoms identified in immunocompromised individuals (Didier et al., 2004). After infection they are able to invade all organs and tissues. Infection with three Encephalitozoon species was shown to originate in either the intestinal or respiratory epithelia (Barbosa et al., 2009; Martinez et al., 2008). Dissemination to other parts of the body may occur, due to the ability of these species to infect macrophages. Specifically, dissemination of $E$. intestinalis can cause nephritis, as well as secondary infections of the sinuses, urinary bladder, and skin. E. cuniculi has been shown to cause keratoconjunctivitis and is capable of infecting the heart, brain, kidneys, and even the tongue (Orenstein, 2003). Similarly, E. hellem has been shown to cause keratoconjunctivitis, and is known to infect the sinuses, urinary bladder, and prostate (Orenstein, 2003). It is generally observed that by far the most common presentation of disease is diarrhea. In immunocompromised individuals, chronic diarrhea may persist and lead to malabsorption and wasting (Hale-Donze and Didier, 2007). Infection has been shown to occur through a variety of sources with the ingestion of contaminated food and water the most prominent route of transmission (Didier et al., 2004). Replication takes place within host cells, which are infected by means of unicellular spores. The microsporidian Encephalitozoon's vary from 1-40 $\mu \mathrm{m}$, making them among the smallest eukaryotes and containing the smallest eukaryotic genomes (Miranda-Saavedra et al., 2007). The first indication of the importance of Th1-type responses in clearance of these parasites came from reports that interferon (IFN)- $y$ null mice could not clear microsporidian infection. The second showed that interleukin (IL)-12 deficient mice succumb to E. cuniculi or E. intestinalis, suggesting that in addition to IFN- $y, \mathrm{IL}-12$ is required for clearance of these fungi (Khan and Didier, 2004). Macrophages play an important role in early innate immune responses to overcoming protozoan infection. However, in the case of mammalian microsporida, macrophages become vehicles for disseminating the parasite throughout the body (Mathews et al., 2009). 


\subsection{Coccidia}

These obligate, intracellular protozoan parasites live in the gut epithelial cells of animals and causes diarrheal disease (coccidiosis), (Helmy, 2010). The disease spreads from one animal to another by contact with infected feces or ingestion of infected tissue. Diarrhea, which may become bloody in severe cases, is the primary symptom. Isosporiasis, a human intestinal disease is caused by the coccidian parasite Isospora belli (Bialek et al., 2002). Isospora is found worldwide, and especially in tropical and subtropical areas. Infection often occurs in immunocompromised individuals (e.g., AIDS patients). More than 248 Isospora species have been described, but most of them are little studied and may not all be distinct species (Lindsay et al., 1997). Cyclospora cayentanensi, is the best studied of the cyst-forming coccidian protozoans responsible for self-limiting diarrhea in humans, the only host it infects. The protozoan lives it's entire lifecycle within the host's gastrointestinal tract epithelial cells (Helmy, 2010). Infection is transmitted through the oral-fecal route from ingestion of oocysts in fecal-contaminated food or water. Its intracellular habitat, small size and inability to take up histological stains, makes diagnosis of Cyclospora cayetanensis difficult. Four methods have thus far been established for positive diagnosis of $C$. cayetanensis: microscopic detection of oocysts in stool samples; identification of oocysts in intestinal fluid/small bowel biopsy specimens; cytological demonstration of oocyst sporulation; and amplification of Cyclospora DNA by polymerase chain reaction (PCR). Though the diarrhea caused by $C$. cayetanensis is self-limiting, relapses frequently occur. At present, the most effective drug for the treatment of the protozoan is a seven-day course of oral trimethoprimsulfamethoxazole. In Sub-Saharan Africa and Egypt, cyclosporiasis was reported to occur in both immunocompromised and immunocompetent patients.

\subsection{Parasitic Worms (Helminthes)}

Intestinal helminths are a group of worm-like intestinal parasites that reside largely in the human gastrointestinal tract. They represent one of the most prevalent forms of parasitic disease. It has been estimated that over a quarter of the world's population is infected with an intestinal worm of some sort, with a variety of roundworm, hookworm, and whipworm species infecting 1.47 billion people, 1.05 billion people, and 1.30 billion people, respectively, (Watkins and Pollitt, 1997). The parasitic worms live and feed off living hosts, absorbing nourishment and protection while disrupting their hosts' nutrient metabolism, resulting in development of weakness and susceptibility to disease (Maizels and Yazdanbakhsh, 2003). The worms live inside the intestines of humans and other animals. Parasitic helminths can be divided into three distinct categories: the cestodes (tapeworms), the nematodes (roundworms) and the trematodes (flukes or flat worms). The principal morphological differences among major helminth families are shown in Table 3. 
Table 3. Morphology of Helminth Families

\begin{tabular}{|c|c|c|c|}
\hline Characteristic & Cestodes & Nematodes & Trematodes \\
\hline Shape & Segmented & $\begin{array}{l}\text { Cylindrical } \\
\text { (round worm) }\end{array}$ & $\begin{array}{l}\text { Unsegmented plane } \\
\text { (flat worm) }\end{array}$ \\
\hline Body Cavity & Absent & Present & Absent \\
\hline $\begin{array}{l}\text { Body Covering } \\
\text { (host-parasite } \\
\text { interface, } \\
\text { functions in: } \\
\text { protection, } \\
\text { absorption and } \\
\text { secretion). }\end{array}$ & $\begin{array}{l}\text { Tegument } \\
\text { (glycocalyx inhibits } \\
\text { host digestive } \\
\text { enzymes. Microvilli } \\
\text { "microtriches", } \\
\text { increase surface } \\
\text { area for nutrient } \\
\text { absorption and } \\
\text { detecting } \\
\text { environmental } \\
\text { cues). }\end{array}$ & $\begin{array}{l}\text { Cuticle } \\
\text { (The nematode cuticle } \\
\text { contains highly cross- } \\
\text { linked collagens and } \\
\text { specialized insoluble } \\
\text { proteins known as } \\
\text { "cuticlins", together } \\
\text { with glycoproteins and li } \\
\text { pids). }\end{array}$ & $\begin{array}{l}\text { Tegument } \\
\text { (glycocalyx inhibits } \\
\text { host digestive } \\
\text { enzymes. Pits and } \\
\text { spines increase } \\
\text { surface area for } \\
\text { absorption of nutrients } \\
\text { and detecting } \\
\text { environment). }\end{array}$ \\
\hline Digestive Tract & Absent & Terminates in Anus & $\begin{array}{l}\text { Terminates in the } \\
\text { Cecum }\end{array}$ \\
\hline Sexual Organs & $\begin{array}{l}\text { Hermaphroditic } \\
\text { (contains both male } \\
\text { and female sex } \\
\text { organs) }\end{array}$ & $\begin{array}{l}\text { Dioecious ( produce } \\
\text { only one type } \\
\text { of gamete, male or } \\
\text { female) }\end{array}$ & $\begin{array}{l}\text { Hermaphroditic,except } \\
\text { schistosomes which } \\
\text { are dioecious }\end{array}$ \\
\hline $\begin{array}{l}\text { Organs of } \\
\text { Attachment }\end{array}$ & $\begin{array}{l}\text { Sucker or bothridia, } \\
\text { and rostellum with } \\
\text { hooks }\end{array}$ & $\begin{array}{l}\text { Lips, teeth, filariform } \\
\text { extremities and dentary } \\
\text { plates } \\
\text { filariasis. (round worm. }\end{array}$ & $\begin{array}{l}\text { Oral and ventral } \\
\text { suckers oracetabulum }\end{array}$ \\
\hline $\begin{array}{l}\text { Human } \\
\text { Diseases }\end{array}$ & Tapeworm Infection & $\begin{array}{l}\text { trichinosis, } \\
\text { elephantiasis, } \\
\text { hookworm), } \\
\text { enterobiasis (pinworm), } \\
\text { onchocerciasis, (river } \\
\text { blindness, trichuriasis, } \\
\text { (whipworm) }\end{array}$ & $\begin{array}{l}\text { Flat worm infection: } \\
\text { Schistosomiasis, } \\
\text { (bilharzia) swimmer's } \\
\text { itch }\end{array}$ \\
\hline
\end{tabular}

\subsection{Parasitic Flat Worms (Cestoidea)}

This class of parasitic flatworms, commonly called tapeworms, of the phylum Platyhelminthes (Cheng, 1986). Its members live in the digestive tract of vertebrates as adults, and often in the bodies of various animals as juveniles. Over a thousand species have been described, and all vertebrate species can be parasitized by at least one species of tapeworm. Several species parasitize humans after being consumed in underprepared meat such as pork, beef, or fish, or as a result of poor hygiene.

\subsection{Parasitic Round Worms (Nematodes)}

Nematodes are the most diverse phylum of pseudo- coelomates, and one of the most diverse of all animals. Nematode species are difficult to distinguish yet over 28,000 nematode species have been described, (Hugot et al., 2001), of which over 16,000 
are parasitic. It has been estimated that the total number of nematode species approaches 1 million (Lambshead, 1993). Unlike cnidarians or flatworms that depend upon absorption of nutrients through their tegument, roundworms have an internal tubular digestive system with openings at both ends. The severe stunting of growth from the round worm Trichuris trichiura (whip worm) infection appears likely to be a reaction at least in part to a chronic inflammatory response accompanied by decreases in plasma insulin-like growth factor-1 (IGF-1), increases in tumor necrosis factor-alpha (TNF-alpha) in the lamina propria of the colonic mucosa and peripheral blood responsible for decreased appetite and intake of all nutrients, as well as an overall decrease in collagen synthesis (Stephenson et al., 2000). The Global Burden of Disease caused by the 3 major intestinal nematodes is estimated as 22.1 million DALYs lost for hookworm, 10.5 million for Ascaris lumbricoides, 6.4 million for Trichuris trichiura, resulting in 39.0 million for the three infections combined (as compared with malaria at 35.7 million), (Stephenson et al., 2000).

\subsection{Parasitic Flukes (Trematodes)}

Parasitic flukes are estimated to include 18,000 to 24,000 species, (Littlewood et al. 2000; Poulin et al., 2005). Nearly all trematodes are parasites of mollusks, turtles, fish and vertebrates. All worm offspring are passed on through poorly-cooked meat, especially pork, fish and beef, contaminated water, feces and mosquitoes. Worm eggs or larvae or even adults enter the human body through the mouth, anus, nose, or skin, with most species attaching themselves to the intestinal tract. With the presence of digestive enzymes, worm eggshells are dissolved, releasing a new worm; unlike its eggshell, the parasitic worm is protected from the body's powerful digestive enzymes by producing a protective keratin layer.

Inflammation of the gut may also occur, resulting in cyst-like structures forming around the egg deposits throughout the body. The host's lymphatic system is also increasingly taxed the longer helminths propagate, as they excrete toxins after feeding. These toxins are released into the intestines to be absorbed by the host's bloodstream. This phenomenon makes the host susceptible to more common diseases such as seasonal viruses and bacterial infections. Present estimates are that over a quarter of the world's population is infected with an intestinal worm of some sort, with roundworm, hookworm, and whipworm infecting 1.47 billion people, 1.05 billion people, and 1.30 billion people, respectively (Watkins \& Pollitt, 1997). In terms of distribution, it has been recently estimated that 400 million, 170 million, and 300 million children are infected with roundworm, hookworm, and whipworm, for a total of almost a billion children (John and William, 2006).

In patients with a heavy worm load, parasite infection is frequently associated with intestinal obstruction, insomnia, vomiting, weakness, and stomach pains (John, David T. and William A. Petri, Jr., 2006), The migration of Ascaris larvae through the respiratory passageways can also lead to temporary asthma and other respiratory symptoms (John and William, 2006).

Also worth considering is the fact that the immune response triggered by helminth infection may drain the body's ability to fight other diseases, making affected individuals more prone to co-infection (Watkins and Pollitt, 1997). There is reasonable evidence indicating that helminthiasis is responsible for the unrelenting prevalence of AIDS and tuberculosis in developing, particularly African, countries (Borkow and Bentwich, 2000). 


\subsection{Helminth Effects on Nutrition}

Intestinal helminths impair human development largely through their impact on nutrition. Intestinal helminth infection has been associated with vitamin deficiencies, stunting of growth, anemia, and protein-energy malnutrition, which in addition to a negative impact on nutrition and immunity also depresses cognitive ability and intellectual development (WHO Expert Committee, 1987). Parasite infection may affect nutrition by competing directly with their hosts for access to nutrients; both whipworm (John, David T. and William A. Petri, Jr.,2006) and roundworm (The World Bank, 1993) are believed to impact their hosts in this way. A more probable source of infection-induced malnutrition is nutrient malabsorption associated with parasite presence in the body. In pigs and humans, Ascaris has been tied to induced lactose intolerance and vitamin A, nitrogen, and fat malabsorption (WHO Expert Committee,1987). Impaired nutrient uptake may result from direct damage to the intestine's mucosal walls as a result of the worms' presence, but it may also be a consequence of chemical imbalances caused by the body's reaction to the helminths (Crompton, 1993). Moreover, it has been suggested that the parasite's release of whipworm and other worm protease inhibitors to defend against digestive processes may impair the breakdown of other nutritious substances (Levinger, 1992; Watkins and Pndollitt, 1997). Finally, worm infections may cause diarrhea and speed "transit time" through the intestinal system, reducing the body's opportunity to capture and retain the nutrients from food (WHO Expert Committee, 1987).

Parasitic worms may also contribute to malnutrition by creating anorexia. A decline in appetite and food consumption due to helminth infection is widely recognized in the literature (The World Bank, 1993). A study of 459 children in Zanzibar reported that mothers noticed spontaneous increases in their children's appetite following a deworming regime (Stoltzfus et. al., 2003). This result was suggested to be a side effect of body's immune response to the worm and release from the stress of combating infection (Watkins and Pollitt, 1997). Specifically, cytokines released in the immune response have been tied to anorexic reactions in animals (Levinger, 1992). Helminths may also affect nutrition by inducing irondeficiency anemia. This is most severe in heavy hookworm infections, as the worms feed directly on the blood of their host. Although the impact of individual worms is limited (each consumes about $.02-.07 \mathrm{ml}$ to $.14-.26 \mathrm{ml}$ of blood daily, respectively), this may be significant in individuals with heavy infections, since they may support hundreds of worms at a given time (WHO Expert Committee, 1987). Researchers Watkins and Pollitt, (1997) predicted, "the blood loss caused by hookworm was equivalent to the daily exsanguination of 1.5 million people." Although whipworm is milder in its effects, it may also induce anemias a result of the bleeding caused by its damage to the small intestine (WHO Expert Committee, 1987). The connection between worm burden and malnutrition is further supported by studies indicating that deworming programs lead to sharp increases in growth; the presence of this result even in older children has lead some researchers to conclude that "it may be easier to reverse stunting in older children than was previously believed" (The World Bank, "World Development Report, 1993: Investing in Health"). Other studies also show a strong correlation between worm burden and malnourishment among school-age children in developing countries (Oberhelman, 1998).

\subsection{Helminth Effects on Cognitive Development}

There are a number of pathways by which parasite burden may affect cognition. For example, difficulty with abstract cognitive tasks, and reduced scores on tests of mental and 
motor development as well as increased fearfulness, inattentiveness, and decreased social responsiveness among very young children (Levinger, 1992). Anemia has also been associated with reduced stamina for physical labor, a decline in the ability to learn new information, and "apathy, irritability, and fatigue" (WHO Expert Committee, 1987).

These connections are supported by a number of deworming studies. For example, using 47 students from the Democratic Republic of the Congo, Boivin and Giardani (1993) found that iron supplements acted as a complement to deworming medication, producing better effects on mental cognition when they were applied in conjunction than when they were individually administered (Boivin, and Giordiani, 1993). The author hypothesized this result was due to the fact that iron supplements may "improve (students') physical well-being to the point of enhancing attention or arousal mechanisms influential in learning and cognitive performance," with deworming medication only acting to extend these benefits by further reducing the tendency to anemia (Boivin and Giordiani, 1993).

Nokes et al. (1992) found that interventions to reduce whipworm infection in 159 Jamaican school children led to better "auditory short-term memory" and "scanning and retrieval of long-term memory;" particularly interesting was his discovery that a nine-week period was all that was necessary for de-wormed students to "catch up" to their worm-free peers in test performance (Nokes et al., 1992). Researchers, Ezeamama and Sakti, studied the worm burden in the Philippines and Indonesia, respectively. Both authors found significant negative impacts of helminthic infection on memory and fluency, findings that are particularly meaningful because they included controls for socioeconomic status, hemoglobin levels, and nutrition (nutritional status and stunting, respectively), (Sakti et al., 1999; Ezeamama et al., 2005).

The day-to-day costs of illness acts as a barrier to children's progress in school as quantified by outcome measures including absenteeism, under-enrollment and chronic attrition (Levinger, 1992). Miguel and Kremer (2004) found that deworming programs improved school attendance by $25 \%$ without affecting test outcomes at all. (Miguel and Kremer, 2004). The Rockefeller Foundation's de-worming programs, lead to a long-term increase in income in addition to increased literacy (Bleakley, 2007).

A drug like albendazole, a benzimidazole containing broad-spectrum anti-helminthic is effective against roundworms, tapeworms, and flukes of domestic animals and humans (Theodorides et al., 1976). This drug is an inexpensive, safe intervention that is not particularly specific, and so can be used quite effectively against all three of the main intestinal helminths or co-infections with any combination of them (The World Bank. "World Development Report 1993: Investing in Health"). Many vertebrates host more than one kind of parasite at a time a concept that is also true in humans. A common assumption is that parasite species rarely interact, because they often exploit different tissues in a host, and this use of discrete resources limits competition (Rohde and Heap, 1998). Recently, it was shown how infection with macroparasites (protozoa and worms) can affect susceptibility to other parasites (e.g., microparasites such as viruses and bacteria) and highlighted how parasite effects may be greater when parasites are considered together rather than measuring the effects of parasite species individually (Telfer et al., 2010). Thus if some human parasites are equally interactive, our current, disease-by-disease approach to modeling and treating infectious diseases may be inadequate suggesting development of multi-component vaccination methods for simultaneous elimination of several parasite and/or pathogen species (Fenton and Perkins, 2010). 
Considering opportunities for parasite interactions, the development of immune cells against one species of parasite or pathogen could cross react with other similar parasite species providing cross-protection against the similar pathogen species (Lafferty, 2010). Thus, infection with one species of a human trematode worm (schistosome) may protect against new infections by another schistosome species (Taylor et al., 1973). Parasites may sometimes facilitate each other's infection. In addition, co-infections with dissimilar parasites can deplete the immune system (Fenton and Perkins, 2010). For example, shedding of the severe acute respiratory syndrome (SARS) virus increases, when a person has a concurrent pulmonary infection (Bassetti et al., 2005). Parasites can also suppress the immune system, opening the door for other pathogens. HIV infection facilitates opportunistic bacterial, fungal, protozoan, and viral pathogens (Selik et al., 1984). Parasitic worms can also suppress the inflammatory response, making it easier for protozoan parasites to infect their hosts (Graham, 2008). Predator-prey models may be applied to examine interactions between host immunity and parasite growth (Fenton and Perkins 2010). A key component of these models is the immune system's functional response, which is based on the relationship between immune activity and parasite load.

\section{VIRAL AND BACTERIAL PATHOGENS}

Due to the lack of adequate sanitation, infectious diseases are rampant in developing countries. Vaccination, either through scarification or parenteral injection has been shown to be effective in eliminating infectious diseases throughout the world. Smallpox pandemics killed many millions of people in Europe, Asia and the Americas over the past 5 centuries. However, massive vaccination campaigns delivered through the efforts of the WHO, have thus far eliminated smallpox from both the industrialized as well as the developing nations. In 1977 the last natural case of Smallpox, was detected in Somalia. In May 1980 the WHO declared the world free from smallpox, after a century long WHO-sponsored vaccination program. In 1983, vaccine distribution to the civilian population was discontinued but is still available for researchers using other orthopoxviruses (like vaccinia and monkey pox virus), in their research. The world, however, is not entirely free of smallpox as the CDC maintains a stock of smallpox (i.e., Variola virus), for vaccine production in the event of bioterrorism attacks or other smallpox outbreaks. The success of vaccine eradication of smallpox from the world and the impending eradication of the neurotoxic infantile paralysis (polio) and the relative success of reassortant rotavirus vaccines in industrialized as well as developing nations suggest that the children of underdeveloped countries, though suffering from malnutrition and a multiple parasite and pathogen load, can mount a significant immune response to enteric pathogens. Polio myelitis (infantile paralysis) has almost been eliminated from the world by another massive WHO vaccination campaign. Due to discontinuation of vaccination program in central and West Africa and Chad, however, three resistant polio strains have produced outbreaks that will require new vaccines. The Bill and Melinda Gates Foundation is contributing support to further vaccine development for eradication of these new polio strains (Larson, 2011). Approximately 95\% vaccine coverage is necessary to generate sufficient "herd immunity" to break the chain of polio transmission as indicated by the WHO. Childhood diseases such as measles are well on their way to being greatly reduced. About 90 percent of worldwide measles deaths occur in children under five. More than 600 million children in more than 60 countries have been vaccinated against measles since 2001 under a program launched by the American Red Cross, the Centers for Disease Control, the United Nations Foundation, UNICEF and the WHO. Deaths fell from an estimated 750,000 in 2000 the year before vaccination efforts began - to 197,000 in 2007. In Africa, where measles claims its biggest toll, deaths fell by $89 \%$, from about 395,000 in 2000 to 45,000 in 2009, (U.N. World Health Organization, 2007). Thus, it is clear that vaccination 
is one of the most successful ways to improve health and prevent disease in developing and resource-limited nations.

The dominant bacterial and viral pathogens that cause infectious disease in economically emerging countries are largely those that cause infections of the intestinal and respiratory mucosae and include Vibrio cholerae, rotavirus species, enterotoxigenic E. coli (ETEC), and pneumococcus species. These three enteric diseases are responsible for an estimated annual 1.0 -1.5 million deaths worldwide. For cholera infection in 2009, a total of 4,946 deaths, out of a total of 221,226 cases from 45 countries were reported. Ninety-nine percent of these deaths, were reported from Africa. ETEC is one of the most common causes of acute watery diarrhea among children and adults in the developing world, causing approximately 400 million diarrheal episodes and 380,000 deaths in children less than 5 years of age in 2005. Rotavirus infection caused approximately 527,000 deaths worldwide in 2004. Many of these deaths were in India and Bangladesh (Kawaii, 2011). In the US, there are about 55,000 hospitalizations for rotavirus dehydration annually resulting in a total of 911,946 deaths/yr. (data reported by the WHO, $2004-2009$ ). Thus, the pathogens responsible for the greatest number of annual deaths of children under 5 years are rotavirus species.

\section{VACCINE EFFICACY IN DEVELOPING NATIONS}

During the last decade, three intact organism oral vaccines were developed to overcome rotavirus infection. Rotashield, an oral rhesus rotavirus reassortant tetravalent vaccine (RRV-TV), was produced by Wyeth Laboratories in 1998, in New Orleans, Louisiana, for an oral vaccine trial involving 1,413 children 1-3 years old was carried out. Protective vaccine effectiveness was $61 \%$ among partially vaccinated children (one or two doses), and $100 \%$ among fully vaccinated children (three doses). Although significantly effective in diarrhea prevention, vaccination with Rotashield was discontinued due to a minor increase intestinal intussusceptions (telescoping of the intestine) was observed in infant compared to the general population. Rotarix (Galaxo Smith-Kline Inc.), is an oral human, live attenuated rotavirus vaccine containing rotavirus strain $\mathrm{G} 1 \mathrm{P}(8)$ specificity. Rotarix was indicated for the prevention of rotavirus gastroenteritis caused by $\mathrm{G} 1$ and non-G1 types (G3, G4, and G9) when administered as a 2-dose series in infants and children. RotaTeq (Merck Inc.) is a live, oral pentavalent reassortant human (VP-7)-bovine (VP4) vaccine that contains five rotaviruses produced by reassortment. The rotavirus A parent strains of the reassortants were isolated from human and bovine hosts. Both Rotarix and RotaTeq are under evaluation in general populations in developing countries as well as in industrialized countries (Plosker 2011; Zeller 2012).

\section{ROTOVIRUS VACCINATION RESULTS}

In Queensland, Australia, in 2007, oral vaccination with was carried out with Rotarix (GSK). In the under 2 years of age group, the vaccine showed a decline in rotavirus infections of $53 \%$ in 2007 , and a decline of $65 \%$ in 2008. In Malawi, Africa, in a 2006, oral Rotarix vaccine trial, vaccine efficacy indicated a $49 \%$ reduction in rotavirus cases in the vaccinated children (Madhi et al., 2010). In Matlab, Bangladesh and in Nha Trang, Vietnam, in 2006, a multicentre, urban and peri-urban location follow up double-blind, placebo-controlled Rotatek vaccine trial resulted in a calculated vaccine protective efficacy of $48.3 \%$. In comparison with rotavirus studies in industrialized world, the protective efficacy of rotavirus vaccination in 
developing countries is about $50 \%$ of the efficacy identified in industrialized countries (Nelson and Glass, Lancet 2010).

In 2009, the WHO recommended rotavirus vaccination be included in all national immunization programs. Because there are so many causes of diarheal disease, the emphasis is on providing rotavirus vaccination within the context of a comprehensive diarheal disease control strategy. This strategy should include factors such as improvement of water quality, hygiene, sanitation, provision for oral rehydration solution, zinc supplementation, as well as improved surveillance and overall case management. WHO and UNICEF are working together in a new accelerated and integrated approach to combat rotavirus diarrhoea and pneumonia, two of the world's most vaccine-preventable diseases, which are linked and together account for more than 35\% of all annual child deaths in the developing world. Linking antigens from these two pathogens into a multicomponent vaccine is a strategy currently being explored by the authors of this review. A recent review estimated that global vaccination with current rotavirus vaccines could prevent about $45 \%$ of worldwide deaths due to rotavirus gastroenteritis, or 228,000 deaths annually (Rheingans et al., 2009).

More than 5,000 children die each day in developing countries due to recurrent diarrheal and respiratory diseases caused by enteric pathogens and the presence of a multiplicity of protozoan and helminth parasites. Vaccination against pathogens and especially diarrheal pathogens was shown to be effective in the developing world. Protective efficacy, however, is reduced by approximately $50 \%$ in comparison with vaccination in industrialized nations. Therefore, based on the information presented in this review, the most likely explanation for the reduced protective efficacy of vaccines in populations of developing countries is malnutrition, parasite load and the chronic diarrheal diseases so pervasive throughout these nations. That the remaining $50 \%$ received protective immunity from vaccination provides a strong case for oral vaccination is an effective program for reducing infectious diseases in developing nations. There is further reason for optimism as the opportunity for improved vaccine efficacy in developing nations can be greatly increased through the application of education and modern nutritional therapy techniques supported by currently available parasite reduction methods.

Oral vaccines generally stimulate the synthesis of low IgG antibody titers and although they stimulate sizable secreted IgA levels, they are generally considered to be significantly less immunostimulatory than injected killed whole organism or attenuated pathogen vaccines. Recent observations (Rheingans et al., 2009), suggest that parasite load in combination with infective pathogens and a nutrient poor diet may together, be responsible for an approximate $50 \%$ reduction in vaccination efficacy based on preliminary evidence generated by the new generation of oral rotavirus reassortant or attenuated oral vaccines Rotarix (Galaxo Smith Kline Inc.) and RotaTech (Merck Inc.), when used to immunize against rotavirus infection in the 1-3 year old child group (Table 4). It may be possible, however, to increase the efficacy and performance of these rotavirus vaccines through delivery of a combination of nutritional therapy and anti-parasite medications in an effort to improve the nutritional status of the vaccinated subjects. Further, genetically engineered subunit vaccines may be expected to be somewhat less immunogenic (in terms of IgG production) than the corresponding whole pathogen vaccines since they contain only one or several immunogenic proteins isolated from the pathogen. 
Table 4. Efficacy of Oral Rotavirus Vaccines

\begin{tabular}{|c|c|c|c|c|}
\hline Location & $\begin{array}{l}\text { Vaccine }(2-3 \\
\text { oral doses) }\end{array}$ & Subjects & $\begin{array}{l}\text { \% Protection } \\
\text { (No } \\
\text { Hospitalization) }\end{array}$ & References \\
\hline $\begin{array}{l}\text { New Orleans, } \\
\text { USA }\end{array}$ & $\begin{array}{l}\text { Rotashield } \\
\text { (Wyeth) }\end{array}$ & $\begin{array}{l}1,413 \text { children } 3-5 \\
\text { yr old } 2 \text {-3 doses }\end{array}$ & $80-100 \%$ & $\begin{array}{l}\text { Prez-Mato et al., Am. J. } \\
\text { Epidemiol. 2002. 156(11), 1049-1055. }\end{array}$ \\
\hline Europe & $\begin{array}{l}\text { Rotarix } \\
\text { (GSK) }\end{array}$ & $\begin{array}{l}3,994 \text { healthy } \\
\text { infants to } 1 \text { yr of } \\
\text { age }\end{array}$ & $87-96 \%$ & $\begin{array}{l}\text { GlaxoSmithKline. Rotarix product } \\
\text { information } 22 \text { February } 2007 . \\
\text { Vesikari T, Karvonen A, Puustinen L, } \\
\text { et al. Pediatr Infect Dis J. 2004; 23, } \\
\text { 937-43. }\end{array}$ \\
\hline $\begin{array}{l}\text { Queensland, } \\
\text { Australia }\end{array}$ & $\begin{array}{l}\text { Rotarix } \\
\text { (GSK) }\end{array}$ & $\begin{array}{l}63,000 \text { children, } \\
\text { younger than } 2 \mathrm{yr}\end{array}$ & $63-89 \%$ & $\begin{array}{l}\text { Field et al., PEDIATRICS Vol. } 126 \\
\text { No. } 3 \text { September 2010; Gentsch et al. } \\
\text { Future Microbiol, 2009, 4(10), 1231- } \\
1234 .\end{array}$ \\
\hline Melawi, Africa & $\begin{array}{l}\text { Rotarix } \\
\text { (GSK) }\end{array}$ & $\begin{array}{l}3,298 \text { children } 6-7 \\
\text { wk old }\end{array}$ & $48 \%$ & $\begin{array}{l}\text { Gentsch et al. Future Microbiol, 2009, } \\
4(10), 1231-1234 .\end{array}$ \\
\hline $\begin{array}{l}\text { Matlab, } \\
\text { Bangladesh }\end{array}$ & $\begin{array}{l}\text { Rotatek } \\
\text { (Merck) }\end{array}$ & $\begin{array}{l}2,036 \text { infants } \\
\text { aged } 4-12 \text { weeks }\end{array}$ & $46 \%$ & $\begin{array}{l}\text { Madhi et al., 2010, New England } \\
\text { Journal of Medicine, vol. } 362 \text { no. 4) }\end{array}$ \\
\hline $\begin{array}{l}\text { Nha Trang, } \\
\text { Vietnam }\end{array}$ & $\begin{array}{l}\text { Rotatek } \\
\text { (Merck) }\end{array}$ & $\begin{array}{l}2,036 \text { infants } \\
\text { aged } 4-12 \text { weeks }\end{array}$ & $46 \%$ & $\begin{array}{l}\text { Zaman et al., 2010.The } \\
\text { Lancet, Volume } 376 \text {, Issue } 9741 \text {, } \\
\text { Pages } 615-623,21 .\end{array}$ \\
\hline
\end{tabular}


Therefore, it may be advantageous to enhance the immunogenicity of these engineered subunit vaccines through fusion of the individual pathogen proteins to suitable effective and safe adjuvant molecules such as the B subunits of cholera toxin, shigatoxin or enterotoxigenic E. coli heat sensitive enterotoxin (LTB), as demonstrated previously (Yu and Langridge, 2001; 2002). Alternatively, it may be possible to further enhance the immunogenicity of oral vaccines through construction of multi-valent vaccines encoding several immunogenic proteins from one pathogen linked to enterotoxin B subunit immunomodulatory molecules (Langridge et. al., unpublished data). Presently, the WHO strongly recommends inclusion of rotavirus vaccines into national immunization programs in regions and countries where vaccine efficacy data suggest the possibility of a significant public health impact and where appropriate infrastructure and financing mechanisms are available to sustain vaccine utilization (World Health Organization Geneva, 2007, Rotavirus vaccines, WHO position paper 1 , No. 32, 82, 285-296).

Recent data gathered on oral rotavirus vaccination in developing countries indicate that vaccine delivery of protective efficacy against diarrhea hospitalization in developing countries due to acute rotavirus infection is reduced by approximately $50 \%$ in comparison with rotavirus hospitalizations in the same age group in industrialized countries (Table 4). The rotavirus vaccination data indicates that there is good reason to remain confident that oral vaccination against diarrheal diseases, while not currently functioning at optimal levels, still remains a reasonably effective form of protection against infectious diarrheal diseases in the developing world in the absence of improved sanitation, purification of water sources, nutritional supplementation and reduction in subject parasite load.

\section{POLITICAL AND SOCIAL PROBLEMS OF HEALTHCARE DELIVERY IN DEVELOPING AND RESOURCE-LIMITED NATIONS}

Health care delivery in the developing world is tied directly to political will, or the extent of government engagement in the execution of health agendas and policies. Specifically community-based governing bodies are the primary enforcers of government programs and policies to improve the health of the local population. Unfortunately, an atmosphere that promotes political leadership and commitment to long-term, sustainable healthcare solutions is significantly hampered. Some of the hampering factors include corruption, burdensome bureaucracies, and high turnover among government official and frequent and unanticipated changes of political regimes. This is particularly true for governments on the African continent where strife and human conflicts exacerbate already serious problems of disease and famine. Even more troublesome is the fact that women, children and those living in absolute poverty are most adversely affected by these unstable and neglectful political systems. Indeed, it will take a combination of technology, financial resources and enlightened self-interest on the part of government leaders to address the complex problem of global health disparity.

In a bid to reduce and ultimately eliminate global health disparities in the developing world, vaccination schedules are often affected. The capacity of federal and state governments to ensure the supply of vaccines to local governments for distribution is unreliable and unsustainable. Children frequently die from a variety of vaccine-preventable diseases such as tetanus, pertussis, tuberculosis, diphtheria and yellow fever because of the inadequate immunization coverage and the attendant failure to develop herd immunity. This elevates the death rate from preventable diseases to about 14 percent of total deaths (WHO immunization surveillance, assessment and monitoring). Immunization rates in Sub-Saharan 
Africa have dramatically decreased over the past few decades. DPT, for example, vaccination rates in the Central African Republic decreased from 82 percent in 1990 to 29 percent in 2000. Similar trends were observed in another African democratic republic where vaccination rates dropped from 79 percent to 33 percent in the same time period (World Bank, 2006). Over time, the benefits and effectiveness of vaccination programs wanes as a result of vaccine shortages, insufficient support for healthcare workers and general lack of continuity and sustainability of the programs. While these issues are complex and deeply rooted in political affairs, the problem of healthcare delivery cannot be blamed solely on government instability and political will alone. A number of researchers suggest that problems of efficient and timely healthcare delivery, including vaccines, in developing countries can be traced to socio-cultural practices as well as religious belief systems. Consequently, any solution to global health disparities must be viewed in a socio-cultural, medical and technological context.

Additional problems that create anxiety about vaccine delivery are related to claims of malpractice by international health organizations. In Mexico, Tanzania and the Philippines, administration of tetanus toxoid vaccines to women became controversial when it was believed that tainted vaccines caused spontaneous abortions (Miller, 2005). Anxiety surrounding these controversies results in a loss of trust in government vaccination programs sponsored by international organizations. Eventually, several vaccination programs were either boycotted or terminated. As a result, the populations of the involved countries became polarized around anti-vaccine campaigns.

\section{CONCLUSIONS}

Recent rotavirus oral vaccine trials in developing countries emphasize that oral vaccination for enteric disease pathogens although approximately half as effective as in industrialized nations, has a significant impact on sparing lives in these countries. Mucosal vaccines have proven to be a valuable asset for preventing childhood infectious disease resulting from Vibrio cholerae, ETEC, Shigella, Salmonella, rotavirus and polio virus - pathogens that routinely invade through the intestine to enter the systemic circulation. To bring mucosal vaccine protection to levels observed in economically affluent countries, improved sanitation, water purification, and especially nutrition (e.g., food, fortified foods and supplementation) will be required, as well as additional improvements in mucosal vaccines and their delivery systems. Effective vaccination against parasites must also be developed in combination with improved forms of nutritional therapy to provide the energy, proteins, lipids and micronutrients required for vaccine restoration of damaged immunity before developing countries can begin to break out of the endless cycle of poverty, malnutrition and disease.

Comparative studies must continue with established and new oral bacterial and viral vaccines as well as with parenteral vaccines to allow an unbiased comparison of vaccine efficacy in the populations of developing countries. Importantly, analysis of vaccine efficacy must be validated through development of accurate and easy to administer assay procedures. Little basic information is currently available concerning mechanisms underlying innate immune responses and adaptive B-cell and T-cell memory in the gut and other mucosal epithelia in children subjected to the abject poverty present in developing countries. Underscoring these unmet needs, an improved understanding of intestinal immune responsiveness during early life is needed to determine the efficacy of mucosal vaccination against enteric pathogens in neonates in economically emerging nations. Attainment of these objectives will permit accelerated development of urgently needed vaccines to reduce current levels of infectious enteric disease mortality in developing nations. 


\section{ACKNOWLEDGEMENTS}

The authors would like to acknowledge Dr. Richard $\mathrm{H}$. Hart for his inspiration and encouragement in the preparation of this review. We also thank, Megan Doyle and Editha Setaiwan of the Global HeathShare at UC Davis for their editorial assistance. This work was supported in part by a grant from the National Institute for Minority Health and Health Disparities (P60MD00222) at the National Institutes of Health.

\section{COMPETING INTERESTS}

Authors have declared that no competing interests exist.

\section{REFERENCES}

Abe, M., Akbar, F., Matsuura, B., Horiike, N., Onji, M. (2003). Defective antigen-presenting capacity of murine dendritic cells during starvation. Nutrition, 19, 265-269.

Ahmed, T., Ahmed, A.M. (2009) Reducing the burden of malnutrition in Bangladesh. BMJ., Nov 4, 339, b4490.

Ahmad Shaikh, M., Marjorie, J., Haskell, Rubhana Raqib, Charles, B., Stephensen (2009). Vitamin A status is associated with T-cell responses in Bangladeshi men. British Journal of Nutrition, 102, 797-802.

Alexander, J.W. (1998). Immunonutrition: the role of omega-3 fatty acids. Nutrition, 14, 627633.

Ambrus, J.L., Sr., Ambrus, J.L., Jr. (2004). Nutrition and infectious diseases in developing countries and problems of acquired immunodeficiency syndrome. Exp Biol Med (Maywood), 229, 464-472.

Ashworth, Ann, Chopra, Mickey, McCoy, David, Sanders, David, Jackson, Debra, Karaolis, Nadina, Sogaula, Nonzwakazi, Schofield, Claire. (2004). WHO guidelines for management of severe malnutrition in rural South African hospitals: effect on case fatality and the influence of operational factors. The Lancet, Volume 363, Issue 9415, 3 April, Pages 1110-1115.

Barnes, D.A., Bonnin, A., Huang, J.X. et al. (1998). A novel multi-domain mucin-like glycoprotein of Cryptosporidium parvum mediates invasion. Mol. Biochem. Parasitol, 96(1-2), 93-110.

Barbosa, J., Rodrigues, A.G., Pina-Vaz, C. (2009). Cytometric approach for detection of Encephalitozoon intestinalis, an emergent agent. Cl in Vaccine Immunol. Jul., 16(7), 1021-4.

Bassetti, S., Bischoff, W.E., Sherertz, R.J. (2005). Are SARS superspreaders cloud adults? Emerg Infect Dis., Apr, 11(4), 637-8.

Beisel, W.R. (1995). Historical overview of nutrition and immunity, with emphasis on vitamin A. f. Nutr. Immunol, 4.

Beisel, W.R. (1996). Nutrition in pediatric HIV infection: Setting the research agenda. Nutrition and immune function: Overview. J Nutr, 126, 2611S-2615S.

Bleakley, H. (2007). Disease and Development: Evidence from Hookworm Eradication in the American South. The Quarterly Journal of Economics, 122, 73. doi. 10.1162/qjec.121.1.73. 
Bialek, R., Binder, N., Dietz, K., Knobloch, J., Zelck, U. (2002). Comparison of autofluorescence and iodine staining for detection of Isospora belli in feces (Free full text). The American Journal of Tropical Medicine and Hygiene, 67(3), 3045, ISSN 0002-9637.

Boivin, M.J., Giordiani, B. (1993). Improvements In cognitive performance for schoolchildren In Zaire, Africa, following an Iron supplement and treatment for intestinal parasites. Journal of Pediatric Psychology, 18(2), 249-264.

Borkow, G., Bentwich, Z. (2000). Eradication of helminthic infections may be essential for successful vaccination against HIV and tuberculosis. Bulletin of the World Health Organization, 78(11).

Briassoulis, George, Olga Filippou, Eugenia Hatzi, Ioannis Papassotiriou, Tassos Hatzis (2005). Early enteral administration of immunonutrition in critically ill children: results of a blinded randomized controlled clinical trial (Nutrition), 21(7), 799-807.

Cabada, M.M., White, A.C. Jr. (2010). Treatment of cryptosporidiosis: Do we know what we think we know? Curr Opin Infect Dis. Oct, 23(5), 494-9.

Caufield et al. (2004). Under-nutrition as an underlying cause of child deaths associated with diarrhea, pneumonia, malaria, and measles. AM. J. Clin. Nutr., 80, 193-198.

Cegielski, J.P., McMurray, D.N. (2004). The relationship between malnutrition and tuberculosis: Evidence from studies in humans and experimental animals. Int $\mathrm{J}$ Tuberc Lung Dis, 8, 286-298.

Center for Disease Control, "Cryptosporidiosis" (2007). Laboratory Identification of Parasites of Public Health Concern. CDC. 5 Sept. http://www.dpd.cdc.gov/dpdx/HTML/Cryptosporidiosis.htm

Cevallos, A.M., Bhat, N., Verdon, R. et al. (2000). Mediation of Cryptosporidium parvum infection in vitro by mucin-like glycoproteins defined by a neutralizing monoclonal antibody. Infect. Immun, 68(9), 5167-75. ).

Chadee, E., Meerovitch, K. (1984). The pathogenesis of experimentally induced amebic liver abscess in the gerbil (Meriones unguiculatus). American Journal of Pathology, 117, 71-80.

Chadee, W.A., Petri Jr., D.J. Innes, Ravdin, J.I. (1987). Rat and human colonic mucins bind to and inhibit adherence lectin of Entamoeba histolytica. Journal Clinical Investigation, 80, 1245-1254.

Chandra, R.K. (1991). Nutrition and immunity: lessons from the past and new insights into the future. Am. J. Clin. Nutr, 53, 1087-1101.

Cheng, T.C. (1986). General Parasitology (2nd edn). Academic Press, Division of Hardcourt Brace \& Company, USA, pp. 402-416. ISBN 0121707552.

Crompton, D.W.T. (1993). Human Nutrition and Parasitic Infection. Cambridge University Press. "Cryptosporidiosis". Centers for Disease Control and Prevention. 2009-02-05.

Czerkinsky, C., Holmgren, J. (2009). Enteric vaccines for the developing world: a challenge for mucosal immunology. Mucosal Immunology, 2, 284-287.

Daren, K., Heyland, M.D., FRCPC, MSc, Frantisek Novak, M.D., John, W., Drover, M.D., FRCSC, Minto Jain, M.D., FRCSC, Xiangyao, Su, PhD, Ulrich Suchner, M.D. (2001). Should Immunonutrition Become Routine in Critically III Patients? JAMA., 286, 944953.

Didier, E.S., Stovall, M.E., Green, L.C., Brindley, P.J., Sestak, K., Didier, P.J. (2004). Epidemiology of microsporidiosis: sources and modes of transmission. Vet. Parasitol, 126, 145-166.

Duriancik, D.M., Denise, E., Lackey, Kathleen, A., Hoag. (2010). Vitamin A as a regulator of antigen presenting cells. J. Nutr, 140, 1395-1399.

Evoy, D., Lieberman, M.D., Fahey, T.J., Daly, J.M. (1998). Immunonutrition: the role of arginine. Nutrition, 14, 611-617. 
Enwonwu, C.O., Falkler, W.A. Jr, Phillips, R.S. (2006). Noma (cancrum oris). Lancet, 368, 147-156.

Ezeamama, Amara, E. et al. (2005). Helminth infection and cognitive impairment among Filipino children. The American Journal of Tropical Medical Hygiene, 72(5), 540-548.

Fenton, A., Perkins, S.E. (2010). Applying predator-prey theory to modelling immunemediated, within-host interspecific parasite interactions. Parasitology, May, 137(6), 1027-38.

Field, C.J., Johnson, I.R., Schley, P.D. (2002). Nutrients and their role in host resistance to infection. J Leukoc Biol, 71, 16-32.

Graham, A.L. (2008). Proc. Natl. Acad. Sci., U.S.A., 105, 566.

Guerrant et al. (1992). Diarrhea as a cause an effect of malnutrition: diarrhea prevents catch-up growth and malnutrition increases diarrhea frequency and duration. Am. J. Trop Hyg, 47, 28-35.

Guerrant, Richard, L., Reinaldo, B. Oriá, Sean, R. Moore, Mônica O.B. Oriá, Aldo, A.M., Lima. (2008). Malnutrition as an enteric infectious disease with long-term effects on child development. Nutr. Rev. September, 66(9), 487-505.

Hagel, I., Lynch, N.R., Di Prisco, M.C., Sanchez, J., Perez, M. (1995). Nutritional status and the IgE response against Ascaris lumbricoides in children from a tropical slum. Trans R Soc Trop Med Hyg, 89, 562-565.

Hagel, I., Lynch, N.R., Puccio, F., Rodriguez, O., Luzondo, R. et al. (2003). Defective regulation of the protective IgE response against intestinal helminth Ascaris lumbricoides in malnourished children. J Trop Pediatr, 49, 136-142.

Hale-Donze, H., Didier, E. (2007). Microsporidioses, Encyclopedia of Life Sciences.

Hall, J.C., Heel, K., McCauley, R. (1996). Glutamine. Br J Surg., 83, 305-312.

Helmy, M.M. (2010). Cyclospora Cayetanensis: A Review, Focusing on What Some of the Remaining Questions about Cyclosporiasis. Infect Disord Drug Targets.

Haque, R., Huston, C.D., Hughes, E., Houpt, Petri, W.A., Jr. (2003). Current concepts: amebiasis. The New England Journal of Medicine, 348, 1565-1573.

Heyland, D.K., MacDonald, S., Keefe, L., Drover, J.W. (1998). Total parenteral nutrition in the critically ill patient: a meta-analysis. JAMA, 280, 2013-2019.

Higgs, S. (2010). Vector Borne and Zoonotic Diseases. Vol.10; No 8, Mary Ann Liebert Pub. ISSN, 1530-3667.

Hisham, Mehanna, Paul C., Nankivell, Jamil, Moledina, Jane, Travis. (2009). Refeeding syndrome - awareness prevention and management. Head Neck Oncol., 1, 4.

Ing, R., Su, Z., Scott, M.E., Koski, K.G. (2000). Suppressed T helper 2 immunity and prolonged survival of a nematode parasite in protein-malnourished mice. Proc Natl Acad Sci. USA, 97, 7078-7083.

John, David T., William, A., Petri, Jr. (2006). Markell and Vogue's Medical Parasitology, 9th Edition. Saunders Elsevier Press.

Kawai, K., O'Brien, M.A. et al. (2012). Burden of rotavirus gastroenteritis and distribution of rotavirus strains in Asia: a systematic review. Vaccine, 30(7), 1244-54.

Keusch, G.T. (1993). Malnutrition and the thymus gland. In: Nutrient Modulation of the Immune Response. (S. Cunningham-Rundles, Ã@dp.), p. 283-299. Marcel Dekker, Inc., New York, NY.

Keusch, Gerald, T., Marguerite Pappaioanou, Mila C. González, Kimberly, A. Scott, Peggy Tsai (2009). Sustaining Global Surveillance and response to emerging Zoonotic diseases, Institute of Medicine And National Research Council of The National Academies, The National Academies Press, Washington, D.C. 350 pages.

Khan, I.A., Didier, E.S. (2004). Insights into the immune microsporidia. Kluwer Acad, Pubs, Boston.

Larson, H.J., Ghinai, I. (2011). Lessons from polio eradication. Nature, 473(7348), 446-7. 
Leleiko, N.S., Walsh, M.J. (1995).Dietary purine nucleotides and the gastrointestinal tract. Nutrition, 11, 725-730.

Levinger, B. (1992). Nutrition, Health, and Learning: Current Issues and Trends. School Nutrition and Health Network Monograph Series, \# 1.

Loukopoulos, P., Komnenou, A., Papadopoulos, E., Psychas, V. (2007). Lethal Ozolaimus megatyphlon infection in a green iguana (Iguana iguana rhinolopa). Journal of Zoo and Wildlife Medicine, 38, 131-134.

David, S., Lindsay, J.P., Dubey, Byron, L., Blagburn. (1997). Biology of Isospora spp. from humans, nonhuman primates, and domestic animals. Clinical Microbiology Reviews, 10(1), 19-34.

Lafferty, K.D. (2010). Microbiology. Interacting parasites. Science, Oct 8, 330(6001), 187-8.

Lambshead, P.J.D. (1993). Recent developments in marine benthic biodiversity research. Oceanis, 19(6), 5-24.

Littlewood, D.T.J., Bray, R.A. (2000). "The Digenea". Interrelationships of the Platyhelminthes. Systematics Association Special, Volume. 60 (1 ed.). CRC., pp. 168185.

Lorente, J.A., Landin, L., De Pablo, R., Renes, E., Liste, D. (1993). L-arginine pathway in the sepsis syndrome. Crit Care Med., 21, 1287-1295.

Maizels, R.M., Yazdanbakhsh, M. (2003). Immune regulation by helminth parasites: cellular and molecular mechanisms. Nat. Rev. Immunol, 3(9), 733-44.

Martínez-Girón, R., Esteban, J.G., Ribas, A., Doganci, L. (2008). Protozoa in respiratory pathology: a review. Eur Respir J. Nov., 32(5), 1354-70.

Mathews, Amber, Anne Hotard, Hollie Hale-Donze (2009). Innate immune responses to Encephalitozoon species infections. Microbes and Infection, 11(12) October, Pages 905-911.

Mehler, Philip, S., Amy, B., Winkelman, Debbie, M., Andersen, Jennifer, L., Gaudiani. (2010). Nutritional Rehabilitation: Practical Guidelines for Refeeding the Anorectic Patient. Nutr Metab, 2010, 62578.

Miguel, Edward, Michael, Kremer. (2004). Worms: Identifying Impacts on Education and Health in the Presence of Treatment Externalities. Econometrica, 72(1), 159-217.

Miranda-Saavedra, D., Stark, M.J., Packer, J.C., Vivares, C.P., Doerig, C., Barton, G.J. (2007). The complement of protein kinases of the microsporidium Encephalitozoon cuniculi in relation to those of Saccharomyces cerevisiae and Schizosaccharomyces pombe. BMC Genomics, Sep 4, 8, 309.

Monaghan, S.R., Kent, M.L., Watral, V.G., Kaufman, R.J., Lee, L.E., Bols, N.C. (2009). Animal cell cultures in microsporidial research: their general roles and their specific use for fish microsporidia. In Vitro Cell Dev. Biol. Anim., 45, 135-147.

Mortimer, L., Chadee, K. (2010). The immunopathogenesis of Entamoeba histolytica. Exp Parasitol, Nov.,126(3), 366-80.

Muller, Olaf, Michael, Krawinkel. (2005). Malnutrition and health in developing countries. CMAJ, Aug. 2, 173(3).

Najera, O., Gonzalez, C., Toledo, G., Lopez, L., Cortes, E. et al. (2001). CD45RA and CD45RO isoforms in infected malnourished and infected well-nourished children. Clin Exp Immunol, 126, 461-465.

Najera, O., Gonzalez, C., Toledo, G., Lopez, L., Ortiz, R. (2004). Flow cytometry study of lymphocyte subsets in malnourished and well nourished children with bacterial infections. Clin Diagn Lab Immunol, 11, 577-580.

Nelson, E.A.S., Roger I. Glass (2010). Rotavirus: realising the potential of a promising vaccine. The Lancet, Vol 376, August 21. 
Neyestani, T.R., Woodward, B. (2005). Blood concentrations of Th2-type immunoglobulins are selectively increased in weanling mice subjected to acute malnutrition. Exp Biol Med (Maywood), 230, 128-134.

Nokes, C. et al. (1992). parasitic helminth infection and cognitive function in school children. Proceedings of the Royal Society of London, 247(247), 77-81.

Orenstein, J.M. (2003). Diagnostic pathology of microsporidiosis. Ultrastruct. Pathol, 27, 141-149.

Phillips, R.S., Enwonwu, C.O., Okolo, S., Hassan, A. (2004). Metabolic effects of acute measles in chronically malnourished Nigerian children. J Nutr Biochem, 15, 281-288.

Poulin, Robert, Serge Morand. (2005). Parasite Biodiversity. Smithsonian, pp. 216.

Rheingans et al. (2009). Economic costs of rotavirus gastroenteritis and cost-effectiveness of vaccination in developing countries. J Infect Dis, 200 (Suppl 1), S16-27.

Rodriguez, L., Gonzalez, C., Flores, L., Jimenez-Zamudio, L., Graniel, J. et al. (2005). Assessment by flow cytometry of cytokine production in malnourished children. Clin Diagn Lab Immunol, 12, 502-507.

Rodriguez, L., Cervantes, E., Ortiz, R. (2011). Malnutrition and gastrointestinal and respiratory infections in children: a public health problem. Int $\mathrm{J}$ Environ Res Public Health, 8(4), 1174-205.

Rohde, K., Heap, M. (1998). Latitudinal differences in species and community richness and in community structure of metazoan endo- and ectoparasites of marine teleost fish. Int J Parasitol, Mar, 28(3), 461-74.

Ryan, K.J., Ray, C.G. (2004). Sherris Medical Microbiology (4th ed.). McGraw Hill, pp.733-8.

Savino, W. (2002). The thymus gland is a target in malnutrition. Eur J Clin Nutr, 56(Suppl 3), S46-S49.

Savino, W., Dardenne, M. (2010). $3^{\text {rd }}$ International Immunonutrition Workshop, Session 2: Micronutrients and the immune system, Nutritional imbalances and infections affect the thymus: consequences on T-cell-mediated immune responses. Proceedings of the Nutrition Society (2010), 69, 636-643.

Scrimshaw, N.S., SanGiovanni J.P. (1997). Synergism of nutrition, infection, and immunity: An overview. Am J Clin Nutr, 66, 464S-477S.

Scrimshaw, N.S., Taylor, C.E., Gordon, J.E. (1968). Interactions of nutrition and infection. Monogr Ser World Health Organ, 57, 3-329.

Selik, R.M., Haverkos, H.W., Curran, J.W. (1984). Acquired immune deficiency syndrome (AIDS) trends in the United States, 1978-1982. Am J Med., Mar, 76(3), 493-500.

Salimonu, L.S. (1993). Natural killer activity in protein-calorie malnutrition. In: Nutrient Modulation of the Immune Response. (S. Cunningham-Rundles, Ã@dp.), p. 359-368. Marcel Dekker, Inc., New York, NY.

Stephensen, C.B. (1999). Burden of infection on growth failure. J Nutr, 129, 534S-538S.

Stephenson, L.S., Holland, C.V., Cooper, E.S. (2000).The public health significance of Trichuris trichiura. Parasitology, 121 Suppl., S73-95.

Stephenson, L.S., Latham, M.C., Ottesen, E.A. (2000). Malnutrition and parasitic helminth infections. Parasitology, 121 Suppl, S23-38.

Stoltzfus, Rebecca, J. et al. (2003). Low dose daily iron supplementation improves iron status and appetite but not anemia, whereas quarterly antihelminthic treatment improves growth, appetite, and anemia in Zanzibar preschool children. The Journal of Nutrition.

Strober, W. (2008). Vitamin A rewrites the ABCs of oral tolerance. Mucosal Immunol, Mar. $1(2), 92-5$.

Taylor, M.G., Nelson, G.S., Smith, M., Andrews, B.J. (1973). Bull. World Health Organ., 49, 57. 
Tectonidis, M. (2006). Crisis in Niger-Outpatient care for severe acute malnutrition. N Engl J Med, 354, 224-227. <-This paper points out a quick and practical approach to remediate acute malnutrition.

Telfer, S., Lambin, X., Birtles, R., Beldomenico, P., Burthe, S., Paterson, S., Begon, M. (2010). Species interactions in a parasite community drive infection risk in a wildlife population. Science, Oct 8, 330(6001), 243-6.

Ten Bruggencate, S.J., Hillyer, L.M., Woodward, B.D. (2001). The proportion of CD45RA(+)CD62L(+) (quiescent-phenotype) $T$ cells within the CD8(+) subset increases in advanced weight loss in the protein- or energy-deficient weanling mouse. J Nutr, 131, 3266-3269.

Theodorides, V.J. et al. (1976). Anthelminitic activity of Albendazole against liver flukes, tapeworms, lung and gastrointestinal roundworms. Experientia, Vol. 32, 702.

Tran et al. (1998). V.Q. Tran, S. Herdman, B.E. Torian and S.L. Reed, The neutral cysteine proteinase of Entamoeba histolytica degrades IgG and prevents its binding. Journal of Infectious Diseases, 177 (1998), pp. 508-511.

United States Department of Health and Human Services (1988). The Surgeon General's report on nutrition and health. Washington (D. C.): DHHS Publishing, pp. 427-463.

Watkins, W.E., Pollitt, E. (1997). 'Stupidity or Worms': Do Intestinal Worms Impair Mental Performance?". Psychological Bulletin, 121(2), 171-91. doi:10.1037/00332909.121.2.171.

Wilmore, D.W., Shabert, J.K. (1998). Role of glutamine in immunologic responses. Nutrition, $14,618-626$.

Woodward, B. (1998). Protein, calories, and immune defenses. Nutr Rev, 56, S84-S92.

Woodward, B., Hillyer, L., Hunt, K. (1999). T cells with a quiescent phenotype (CD45RA+) are overabundant in the blood and involuted lymphoid tissues in wasting protein and energy deficiencies. Immunology, 96, 246-253.

World Bank. (1993). World Development Report: Investing in Health.

WHO. (1997). WHO: Amoebiasis, 1997. WHO Weekly Epidemiologic Record, vol. 72, pp. 97-100.

World Health Organization. (2005). Nutrition: Challenges. Available: http://www.who.int/ nutrition/challenges.

WHO, Report of a Expert Committee (1987). Prevention and Control of Intestinal Parasitic Infections. World Health Organization, Technical Report Series, 749.

Wu D, Meydani SN. (1998). n-3 polyunsaturated fatty acids and immune function. Proc Nutr Soc., 57, 503-509.

Leońska-Duniec, A., Adamska, M. (2010). Biology, epidemiology and diagnostics of pathogenic waterborne protozoan parasites. Wiad Parazytol., 56(2), 125-32.

Xiao, L. (2010). Molecular epidemiology of cryptosporidiosis: An update. Experimental Parasitology, 124(1), January, Pages 80-89.

Xiao, Feng (2008). Zoonotic cryptosporidiosis. FEMS Immunology and Medical Microbiology, 52, 309-323.

Yu, J., Langridge, W.H.R. (2001). A plant-based multicomponent vaccine protects mice from enteric diseases. Nature Biotechnology, June, 19, 548-552.

$\mathrm{Yu}$, J., Carter, J.E., Langridge, W.H.R. (2002). Edible Vaccines, in Vaccines: Delivery Systems, Gobel, W. and Dietrich, G. eds., Horizon Press, Chapter 16, 369-397.

(C) 2012 Langridge et al.; This is an Open Access article distributed under the terms of the Creative Commons Attribution License (http://creativecommons.org/licenses/by/3.0), which permits unrestricted use, distribution, and reproduction in any medium, provided the original work is properly cited. 